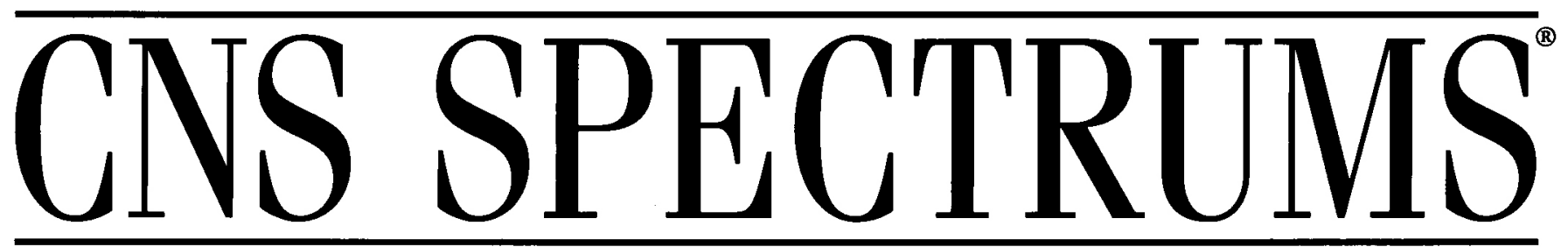

The International Journal of Neuropsychiatric Medicine 6

\title{
Body Dysmorphic Disorder: Conceptualization and Treatment
}

The Importance of Aesthetics in Body Dysmorphic Disorder D.M. Veale and C. Lambrou

Neuroanatomical Correlates and Somatosensorial

Disturbances in Body Dysmorphic Disorder

J.A. Yaryura-Tobias, F. Neziroglu, and M. Torres-Gallegos

ORIGINAL RESEARCH

Interpretive Biases for Ambiguous Information in Body Dysmorphic Disorder

U. Bublmann, S. Wilhelm, R.J. McNally, et al

\begin{tabular}{|c|}
\hline 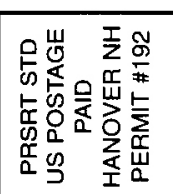 \\
\hline
\end{tabular}

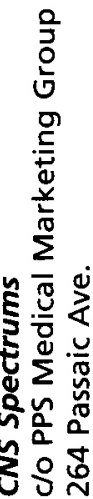

ORIGINAL RESEARCH

Computerized Perceptual

Analysis of Patients with

Body Dysmorphic Disorder

JA. Yaryura-Tobias, F. Neziroglu,

R. Chang, S. Lee, A. Pinto, and L. Donohue

Pharmacologic Treatment of

Body Dysmorphic Disorder:

Review of the Evidence

and a Recommended

Treatment Approach

K.A. Phillips

A Review of Cognitive and

Behavior Treatment of Body Dysmorphic Disorder

F. Neziroglu and S. Khemlani-Patel

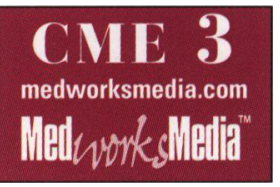

CNS Spectrums is indexed by EMBASE/Excerpta Medica, DIALOG, SilverPlatter, OVID, and Lexis-Nexis, and is the official journal of the International Neuropsychiatric Assoc. 
In a teratology study in rabbits, an increased incidence of postimplantation fetal loss occurred in dams exposed to 60 , 300 and $1500 \mathrm{mg} / \mathrm{kg} / \mathrm{day}$, or less than approximately $1 / 4$ to 8 times the maximum human dose on a $\mathrm{mg} / \mathrm{m}^{2} \mathrm{basis}$. There are no adequate and well-controlled studies in pregnant women. Because animal reproduction studies are not always predictive of human response, this drug should be used during pregnancy only if the potential benefit justifies the
potential risk to the fetus. Use in Nursing Mothers Gabapentin is secreted into human milk following oral

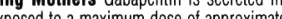
Because the elfect on the nursing infant is unknown. Neurontio should be used in women who are nursing only if the benefits clearly outweigh the risks. Pediatric Use Effectiveness in pediatric patients below the age of 3 years has not been established (see CLINICAL PHARMACOLOGY, Clinical Studies). Geriatric Use Clinical studies of Neurontin did not include sufficient numbers of subjects aged 65 and over to determine whether they responded differently from younger subjects. Other reported clinical experience has not identified differences in responses between the elderly and younger patients. In general, dose selection for an elderly patient should be cautious, usually starting at the low end of the dosing range, reflecting the greater frequency of decreased hepatic, renal, or cardiac function, and of concomitant disease or other drug therapy. This drug is known to be substantially excreted by the kidney, and the risk of toxic reactions to this drug may be greater in patients with impaired renal function. Because elderly patients are more likely to have decreased renal
function, care should be taken in dose selection, and it may be useful to monitor renal function (see CLINICAL function, care should be taken in dose selection, and it may be useful to monitor renal
PHARMACOLOGY, ADVERSE REACTIONS, and DOSAGE AND ADMINISTRATION sections).

\section{ADVERSE REACTIONS}

The most commonly observed adverse events associated with the use of Neurontin in combination with other antiepileptic drugs in patients $>12$ years of age, not seen at an equivalent frequency among placebo-treated patients, were somnolence, dizziness, ataxia, fatigue, and nystagmus. The most commonly observed adverse events reported with the use of Neurontin in combination with other antiepileptic drugs in pediatric patients 3 to 12 years of age, not seen at an equal frequency among placebo-treated patients, were viral infection, fever, nausea and//or vomiting, somnolence, and hostility (see WARNINGS, Neuropsychiatric Adverse Events). Approximately $7 \%$ of the 2074 patients $>12$ years of age and approximately $7 \%$ of the
449 pediatric patients 3 to 12 years of age who received Neurontin in premarketing clinical trials discontinued treatment because of an adverse event The adverse events most commonly associated with withdrawal in patients $>12$ vears of age were somnolence $(1.2 \%)$, ataxia $(0.8 \%$ ), tatigue $(0.6 \%)$, nausea and/or vomiting $(0.6 \%)$, and dizziness $(0.6 \%)$. The adverse events most commonly associted with withdrawal in pediatric patients were emotional lability $(1.6 \%)$, hostility $(13 \%)$, and hyperkinesia (1.1\%) Incidence in Controlled Clinical Trials Table 1 lists treatment-emergent signs and symptoms that occurred in teast $1 \%$ of Neurontin-treated patients $>12$ years of age with epilepsy participating in placebo-controlled trials and were numerically more common in the Neurontin ${ }^{*}$ group. In these studies either Neurontin or placebo was added to the patient's current antiepileptic drug therapy. Adverse events were usually mild to moderate in intensity. The prescriber should be aware that these figures, obtained when Neurontin ${ }^{\otimes}$ was added to concurrent antiepileptic drug therapy, cannot be used to predict the frequency of adverse events in the course of usual medical practice where patient characteristics and other factors may differ from those prevailing during clinical studies. Similarly the cited frequencies cannot be directly compared with figures obtained from other clinical investigations involving different treatments, uses, or investigators. An inspection of these frequencies, however, does provide the prescribing physician with one basis to estimate the relative contribution of drug and nondrug factors to the adverse event incidences in the population studied.

TABLE 1. Treatment-Emergent Adverse Event Incidence in Controlled Add-0n Trials in Patients $>12$ Years of Age (Events in at least $1 \%$ of Neurontin patients and numerically more frequent than in the placebo group)

\begin{tabular}{|c|c|c|c|c|c|}
\hline$\frac{\text { Body System/ }}{\text { Adverse Event }}$ & $\begin{array}{c}\text { Neurontin }^{(3 a} \\
N=543 \\
\%\end{array}$ & $\begin{array}{c}\text { Placebo }{ }^{a} \\
N=378 \\
\%\end{array}$ & $\frac{\text { Body System/ }}{\text { Adverse Event }}$ & $\begin{array}{c}\text { Neurontin } \\
\mathrm{N}=543 \\
\%\end{array}$ & $\begin{array}{c}\text { Placebo } \\
\mathrm{N}=378 \\
\%\end{array}$ \\
\hline \multicolumn{3}{|l|}{ Body As A Whole } & \multicolumn{3}{|l|}{ Nervous System (cont'd) } \\
\hline Fatigue & 11.0 & 50 & Tremor & 6.8 & 3.2 \\
\hline Weight Increase & 2.9 & 1.6 & Nervousness & 2.4 & 1.9 \\
\hline Back Pain & 1.8 & 0.5 & Dysarthria & 2.4 & 0.5 \\
\hline Peripheral Edema & 1.7 & 0.5 & Amnesia & 2.2 & 0.0 \\
\hline \multicolumn{3}{|l|}{ Cardiovascular } & Depression & 1.8 & 1.1 \\
\hline Vasodilatation & 1.1 & 0.3 & Thinking Abnormal & 1.7 & 1.3 \\
\hline \multicolumn{3}{|l|}{ Digestive System } & Twitching & 1.3 & 0.5 \\
\hline Dyspepsia & 2.2 & 0.5 & Coordination Abnormal & 1.1 & 0.3 \\
\hline Mouth or Throat Dry & 1.7 & 0.5 & Respiratory System & & \\
\hline Constipation & 1.5 & 0.8 & Rhinitis & 4.1 & 3.7 \\
\hline Dental Abnormalities & 1.5 & 0.3 & Pharynoitis & 2.8 & 1.6 \\
\hline Increased Appetite & 1.1 & 0.8 & Coughing & 1.8 & 1.3 \\
\hline \multicolumn{3}{|c|}{ Hematologic and Lymphatic Systems } & Skin and Appendages & & \\
\hline Leukopenia & 1.1 & 0.5 & Abrasion & 1.3 & 0.0 \\
\hline \multicolumn{3}{|l|}{ Musculoskeletal System } & Pruritus & 1.3 & 0.5 \\
\hline Myalgia & 2.0 & 1.9 & Urogenital System & & \\
\hline & 1.1 & 0.8 & Impotence & 1.5 & 1.1 \\
\hline \multicolumn{3}{|l|}{ Nervous System } & Special Senses & & \\
\hline Somnolence & 19.3 & 8.7 & Diplopia & 5.9 & 1.9 \\
\hline Dizziness & 17.1 & 6.9 & Amblyopia ${ }^{0}$ & 4.2 & 1.1 \\
\hline Ataxia & 12.5 & 5.6 & Laboratory Deviations & & \\
\hline Nystagmus & 8.3 & 4.0 & WBC Decreased & 1.1 & 0.5 \\
\hline
\end{tabular}

a Plus background antiepileptic drug therapy. ${ }^{\circ}$ Amblyopia was often described as blurred vision.

Other events in more than $1 \%$ of patients $>12$ years of age but equally or more frequent in the placebo group included: headache, viral intection, fever, nausea and/or vomiting, abdominal pain, diarrhea, convulsions, confusion, insomnia emotional lability, rash, acne. Among the treatment-emergent adverse events occurring at an incidence of at least $10 \%$ Neurontin-treated patients, somnolence and ataxia appeared to exhibit a positive dose-response relationship. The overall incidence of adverse events and the types of adverse events seen were similar among men and women treated with Neurontin ${ }^{*}$. The incidence of adverse events increased slightly with increasing age in patients treated with either Neurontin ${ }^{*}$ or placebo. Because only $3 \%$ of patients (28/921) in placebo-controlled studies were identified as nonwhite (black or
other) there are insufficient data to support a statement regarding the distribution of adverse events by race. Table 2 lists other), there are insufficient data to support a statement regarding the distribution of adverse events by race. Table 2 lists
treatment-emergent signs and symptoms that occurred in at least $2 \%$ of Neurontin-treated patients 3 to 12 years of age with epilepsy participating in placebo-controlled trials and were numerically more common in the Neurontin group. Adverse events were usually mild to moderate in intensity.

TABLE 2. Treatment-Emergent Adverse Event Incidence in Pediatric Patients Age 3 to 12 Years in a Controlled Add-On Tria

(Events in at least 2\% of Neurontin patients and numerically more frequent than in the placebo group)

\begin{tabular}{|c|c|c|c|c|c|}
\hline $\begin{array}{l}\text { Body System/ } \\
\text { Adverse Event }\end{array}$ & $\begin{array}{c}\text { Neurontin }^{2} \\
N=119 \\
\%\end{array}$ & $\begin{array}{c}\text { Placebo }^{a} \\
N=128 \\
\%\end{array}$ & $\frac{\text { Body System/ }}{\text { Adverse Event }}$ & $\begin{array}{c}\text { Neurontin }^{\mathrm{a}} \\
\mathrm{N}=119 \\
\%\end{array}$ & $\begin{array}{c}\text { Placebo } \\
\mathrm{N}=128 \\
\%\end{array}$ \\
\hline \multirow{8}{*}{$\begin{array}{l}\text { Body As A Whole } \\
\text { Viral Infection } \\
\text { Fever } \\
\text { Weight Increase } \\
\text { Fatigue } \\
\text { Digestive System } \\
\text { Nausea and/or Vomiting }\end{array}$} & & & Nervous System & & \\
\hline & 10.9 & 3.1 & Somnolence & 8.4 & 4.7 \\
\hline & 10.1 & 3.1 & Hostility & 7.6 & 2.3 \\
\hline & 3.4 & 0.8 & Emotional Lability & 4.2 & 1.6 \\
\hline & 3.4 & 1.6 & Dizziness & 25 & 1.6 \\
\hline & & & Hyperkinesia & 2.5 & 0.8 \\
\hline & 8.4 & 7.0 & Respiratory System & & \\
\hline & & & $\begin{array}{l}\text { Bronchitis } \\
\text { Respiratory Infection }\end{array}$ & $\begin{array}{l}3.4 \\
2.5\end{array}$ & $\begin{array}{l}0.8 \\
0.8\end{array}$ \\
\hline
\end{tabular}

a Plus background antiepileptic drug therapy.

Other events in more than $2 \%$ of pediatric patients 3 to 12 years of age but equally or more trequent in the placebo group included: pharyngitis, upper respiratory intection, headache, rhinitis, convulsions, diarrhea, anorexia, coughing, and otitis media.

Other Adverse Events Observed During All Clinical Trials Neurontin ${ }^{8}$ has been administered to 2074 patients $>12$ years of age during all clinical trials, only some of which were placebo-controlled. During these trials, all adverse events were recorded by the clinical investigators using terminology of their own choosing. To provide a meaningful estimate of the proportion of individuals having adverse events, similar types of events were grouped into a smaller number of standardized categories using modified COSTART dictionary terminology. These categories are used in the listing below. The frequencies presented represent the proportion of the 2074 patients $>12$ years of age exposed to Neurontin who experienced an event of the type cited on at least one occasion while receiving Neurontin*. All reported events are included except those already listed in the previous table, those too general to be informative, and those not reasonably associated with the use of the drug. Events are further classified within body system categories and enumerated in order of decreasing frequency using the following definitions: frequent adverse events are defined as those occurring in at least $1 / 100$ patients; intrequent adverse events are those occurring in 1/100 to 1/1000 patients; rare events are those occurring
in fewer than 1/1000 patients. Body As A Whole: Frequent: asthenia, malaise, face edema; Infrequent: allergy, generalized edema, weight decrease, chill; Rare: strange feelings, lassitude, alcohol intolerance, hangover effect. Cardiovascular System: Frequent: hypertension; Infrequent: hypotension, angina pectoris, peripheral vascular disorder, palpitation lathyrar

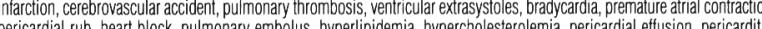
Dercardial

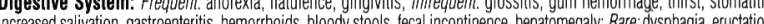
pancreatitis pentic panceritis, pept hernia, comas System: Pare hyperthyroid, appearance. Hematologic and Lymphatic System: Frequent purpura most often described as bruises resulting from appearance. Hematologic and Lymphalic system. physical trauma; Inrrequent: anemia, thrombocytopenia, lymphadenopathy; Rare: WBC count increased, lymphocytosis, nonarthritis joint stiffness, idint swelling, positive Romberg test: Rare: costochondritis, osteoporosis, bursitis, contracture Nervous System: Frequent: vertigo, hyperkinesia, paresthesia, decreased or absent reflexes, increased reflexes, anxiety hostility; Infrequent: CNS tumors, syncope, dreaming abnormal, aphasia, hypesthesia, intracranial hemorrhage, hypotoni hostility; Intrequent: CNS tumors, syncope, dreaming abnormal, aphasia, hypesthesia, intracranial hemorrhage, hypotonia dysesthesia, paresis, dystonia, nemiplegia, facial paralysis, stupor, cerebellar dystunction, positive Babinski sigin, decrease
position sense, subdural hematoma, apathy, hallucination, decrease or loss of libido, agitation, paranoia, depersonalization,

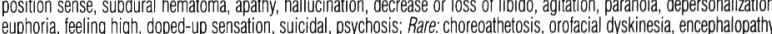
euphoria, teeling high, doped-up sensation, suicidal, psychosis, Rare. choreoalhetosis, orolacial dyskinesia, encephalopathy, nerve palsy, personality disorder, increased libido, suddued temperament, apraxia, ine motor control disorder, meningismus,
local myoclonus, hyperesthesia, hypokinesia, mania, neurosis, hysteria, antisocial reaction, suicide gesture. Respiratory System: Frequent: pneumonia; Intrequent: epistaxis, dysonea, annea; Rare: mucositis, aspiration pneumonia, hyperventilation hiccup, laryngitis, nasal obstruction, snoring, bronchospasm, hypoventilation, lung edema. Dermatological: Intrequent: alopecia, eczema, dry skin, increased sweating, unticaria, hirsutism, seborrhea, cyst, herpes simplex, Rare: herpes zoster, skin discolor, skin papules, photosensitive reaction, leg ulcer, scalp seborrhea, psoriasis, desquamation, maceration, skin nodules, subcutaneous nodule, melanosis, skin necrosis, local swelling. Urogenital System: Inifrequent: hematuria, dysuria, urination trequency, cystitis, urinary retention, urinary incontinence, vaginal hemorrhage, amenorrhea, dysmenorrhea, menorrhagia trailure cancer, unable to climax, ejaculation abnormal: Rare: kidney pain, leukorrhea, pruritus genital, renal stone, acus Specia Senses: Frequent abnormal vision; Infrequent: cataract, con unctivitis, eyes dry, eye pain, visual field defect. photophobia bilateral or unilateral ptosis, eye hemorrhage, hordeolum, hearing loss, earache, tinnitus, inner ear intection, ottitis, taste loss, unusual taste, eye twitching, ear fullness; Rare: eye itching, abnormal accommodation, perforated ear drum, sensitivity to noise, eye focusing problem, watery eves, retinopathy, glaucoma, iritis, corneal disorders, lacrimal dysfunction, degenerative eye changes, blindness, retinal degeneration, miosis, chorioretinitis, strabismus, eustachian tuoe dystunction, labyrinthitis, otitis externa, odd smell. Adverse events occurring during clinical trials in 449 pediatric patients 3 to 12 years of age treated with gabapentin that were not reported in adjunctive trials in adults are: Body As A Whole: dehydration, infectious mononucleosis. Digestive System: hepatitis. Hemic and Lymphatic System: coagulation defect. Nervous System: aura disappeared occipital neuralgia. Psychobiologic Function: sleepwalking. Respiratory System: pseudocroup, hoarsenes Postmarketing and Other Experience In addition to the adverse experiences reported during clinical testing of Neurontin the following adverse experiences have been reported in patients receiving marketed Neurontin? have not been listed above and data are insufficient to support an estimate of their incidence or to establish causation. The
listing is alphabetized: angioedema, blood glucose fluctuation, erythema multiforme, elevated liver function tests, fever, hyponattemla, Jaundice, Stevens-Johnson syndrome.

DRUG ABUSE AND DEPENDENCE

The abuse and dependence potential of Neurontin ${ }^{9}$ has not been evaluated in human studies OVERDOSAGE

A lethal dose of gabapentin was not identified in mice and rats receiving single oral doses as high as $8000 \mathrm{mg} / \mathrm{kg}$. Sign of acute toxicity in animals included alaxia, labored breathing, ptosis, sedation, hypoactivity, or excitation. Acute or overdoses of Neurontin up to 49 grams have been reported. In these cases, double vision, slurred speech, drowsiness, lethargy and diarriea were observed. All patients recovered with suppontive care. Gabapentin can be removed by hemodialysis. Although hemodialysis has not been performed in the few overdose cases reported, it may be indicated by the patient's clinical state or in patients with significant renal impairment.

\section{DOSAGE AND ADMINISTRATION}

Neurontin is recommended for add-on therapy in patients 3 years of age and older. Effectiveness in pediatric patients below the age of 3 years has not been established. Neurontin is given orally with or without food. Patients $>12$ Years of Age: The effective dose of Neurontin is 900 to $1800 \mathrm{mg} / \mathrm{day}$ and given in divided doses (three times a day) using 300 - or $400-\mathrm{mg}$ capsules or 600 - or 800 -mg tablets. The starting dose is $300 \mathrm{mg}$ three times a day. If necessary, the dose

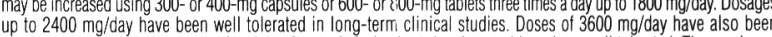
administered to a small number of patients for a relatively short duration and have been well toleraed. The maximum time between doses in the T.I.D. schedule should not exceed 12 hours. Pediatric Patients Age 3-12 Years: The starting dose should range from $10-15 \mathrm{mg} / \mathrm{kg} /$ day in 3 divided doses, and the effective dose reached by upward titration over period of approximately 3 days. The effective dose of Neurontin in patients 5 years of age and older is $25-35 \mathrm{mg} / \mathrm{kg} / \mathrm{day}$ and given in divided doses (three times a day). The effective dose in pediatric patients ages 3 and 4 years is $40 \mathrm{mg} / \mathrm{kg} / \mathrm{day}$ and given in divided doses (three times a day). (See CLINICAL PHARMACOLOGY, Pediatrics.) Neurontine may be administered as the oral solution, capsule, or tablet, or using combinations of these formulations. Dosages up to $50 \mathrm{mg} / \mathrm{kg} /$ day have been well tolerated in a long-term clinical study. The maximum time interval between doses should not exceed 12 hours. It is not necessary to monitor gabapentin plasma concentrations to optimize Neurontin ${ }^{\mathbb{e}}$ therapy. Further, because there are no significant pharmacokinetic interactions among Neurontin ${ }^{e}$ and other commonly used antiepileptic drugs, the addition of Neurontin does not alter the plasma levels of these drugs appreciably. If Neurontin is discontinued and/or an alternate anticonvulsant medication is added to the therapy, this should be done gradually over a minimum of 1 week. Creatinine clearance is difficult to measure in outpatients. In patients with stable renal function, creatinine clearance $(\mathrm{C} C r)$ can be reasonably well estimated using the equation of Cockcrott and Gault:

$$
\text { for temales } \quad \mathrm{C}_{\mathrm{Cr}}=(0.85)\left(140 \text {-age) }(\text { weight }) /\left[(72)\left(\mathrm{SCr}_{\mathrm{r}}\right)\right]\right.
$$$$
\text { for males } \quad \mathrm{C}_{\mathrm{Cr}}=(140 \text {-age) })(\text { weight }) /\left[(72)\left(\mathrm{SC}_{\mathrm{C}}\right)\right]
$$

where age is in years, weight is in kilograms and $\mathrm{SCr}_{\mathrm{r}}$ is serum creatinine in $\mathrm{mg} / \mathrm{dL}$. Dosage adjustment in patients $\geq 12$ years of age with compromised renal function or undergoing hemodialysis is recommended as follows:

TABLE 3. Neurontin ${ }^{\oplus}$ Dosage Based on Renal Function

\begin{tabular}{ccc}
\hline $\begin{array}{c}\text { Renal Function } \\
\begin{array}{c}\text { Creatinine Clearance } \\
(\mathrm{mL} / \mathrm{min})\end{array}\end{array}$ & $\begin{array}{c}\text { Total Daily Dose } \\
\text { (mg/day) }\end{array}$ & $\begin{array}{c}\text { Dose Regimen } \\
\text { (mg) }\end{array}$ \\
\hline$>60$ & 1200 & 400 T.I.D. \\
$30-60$ & 600 & 300 B.I.D. \\
$15-30$ & 300 & 300 Q.D. \\
$<15$ & 150 & 300 Q. O.D. \\
Hemodialysis & - & $200-300^{\circ}$ \\
\hline
\end{tabular}

${ }^{a}$ Every other day. ${ }^{\circ}$ Loading dose of 300 to $400 \mathrm{mg}$ in patients who have never received Neurontin", then $20010300 \mathrm{mg}$ Neurontin ${ }^{\circ}$ following each 4 hours of hemodialysis.

The use of Neurontin in patients < 12 years of age with compromised renal function has not been studied.

Re only

\section{PARKE-DAVIS}

\section{PARKE-DAVIS}

A Pfizer Company

C1999, PDPL

Rev. 0, July 2001

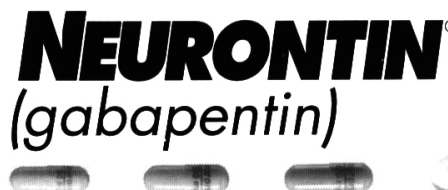

$100 \mathrm{mg} \quad 300 \mathrm{mg}$

$400 \mathrm{mg}$

$600 \mathrm{mg}$

$800 \mathrm{mg}$

$250 \mathrm{mg} / 5 \mathrm{~mL}$

Products pictured are not actial size. 


\section{NEURONTIN" (gabapentin) capsules \\ NEURONTIN ${ }^{\text {(gabapentin) tablets }}$ \\ NEURONTIN ${ }^{\circledR}$ (gabapentin) oral solution \\ Befor prescribing loges see full prescribing intormation. A Briel Summary tollows.}

\section{INDICATIONS AND USAGE}

Neurontin ${ }^{E}$ (gabapentin) is indicated as ad unctive therapy in the treatment of partial seizures with and without secondary generalization in patients over 12 years of age with epiliepsy. Ne
treatment of partial seizures in ped iatric patilients age $3-12$ years.

\section{CONTRAINDICATIONS}

Neurontin ${ }^{R}$ is contraindicated in patients who have demonstrated hyoersensitivity to the drug or its incredients WARNINGS

Neuropsychiatric Adverse Events-Pediatric Patients 3-12 Years of Age Gabapentin use in pediatric patients most significant of these age is associated with the occurrence of cenitral nervous system related adverse events. The problens), 2) hostility inclucing assited into the following categories: 1) emotional lability (primari y belhavioral change in school performance, and 4) hyperkinesia (orimarily restlessoss and hyeractivity). Among the gabacentintreated patients. most of the events were mild to moderate in intensity in controlled trials in pediatric oatients 3-12 years (ablity $6 \%$ (gabapentin-treated patients) vs $1.3 \%$ (placebotreated patients;; hostility $5.2 \%$ vs $1.3 \%$; hyoerkinesia $4.7 \%$ vs $2.9 \%$; and thought disorder $1.7 \%$ vs $0 \%$. One of these events, a report of hositicy, was considered serious. Discontinuation of cabasentin treatment occurred in $1.3 \%$ al patients reporting emotional lability and hyperkinesia and $0.9 \%$ of gabapentin-treated patients reporting hostility and thought disorder. One placebo-treated patient $(0.4 \%)$ withdrew due to emotional labil ty. Withdrawal Precipitated Seizure, Status Epilepticus Antieplieptic drugs should not be abruptly discontinued because of the possibility of increasing seizure frequency. In the placebo-controlled studies in patients $>12$ years of age, the incidence of status epilepticus in patients receiving Neurontin" was $0.6 \%$ ( 3 of 543 ) versus $0.5 \%$ in patients receiving placebo (2 of 378 ). Among the 2074 patients treated with Neurontiri" across all studies (controlled and uncontrolled) $31(1.5 \%$ ) had status epilepticus. of these, 14 patients had no prior history of status epilepticus either before treatment or while on other medications. Because adequate historical data are not aval lable, it is impossible to say whether or not treatrment with Neurontin" is associated with a higher or lower rate of status epilepticus than would be expected to occur in a similar population not treated with Neurontin ${ }^{\otimes}$. Tumorigenic Potential in standard prectinical in vivo lifetime carcinogenicity studies, an unexpectedly high incidence of pancreatic acinar adenocarcinomas was identified in male, but not temale, rats. (See PRECAUIIONS: Carcinogenesis, Mutagenesis, Impairment of Fertility.) The clinical significance of this tinding is unknown. Clinical experience during gabapentin's premarketing development provides no direct means to assess its potential for inducing tumors in humans. In clinical studies comprising 2085 patient-years of exposure, new tumors were reported in 10 patients (2 breast, 3 brain, 2 lung, 1 adrena: 1 non-Hodgkin's lymphoma, 1 endometrial carcinoma in situ), and preexisting tumors worsened in 11 patents ( 9 brain, 1 breast, 1 prostate) during or up to 2 years following discontinuation of Neurontin. Without knowledge of the background incidence and recurrence in a similar population not treated with Neuronting, it is impossible to know whether the incidence seen in this cohort is or is not affected by treatment. Sudden and Unexplained Deaths During the course of premarketing developrnent of Neurontin"s; 8 sudden and unexplained deaths were recorded among a cohort of 2203 patients treated (2103 patient-years of exposure). Some of these could represent seizure-related deaths in which the seizure was not observed, e.g., at night. This represents an incidence
of 0.0038 deaths per patient-year. Although this rate exceeds that expected in a healthy population matched for age and sex, it is within the range of estimates for the incidence of sudden unexplained deaths in patients with epilepsy not receiving Neurontin (ranging fiom 0.0005 tor the gereral populat on of epileptics, to 0.003 in a clirical rrial popu ation similar to

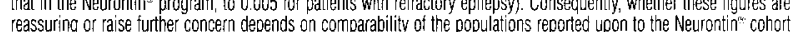
reassuring or rase turther concern depends on

\section{PRECAUTIONS}

Information for Patients Patients should be instructed to take Neurontin" only as prescribed. Patients should be advised on Neurontin"s to gauge whether or not it affects their mental and/or motor pertornance adversely. Laboratory Tests Clinical trials data do not indicate hat routine monitoring of clinica laboratory parameters is necessary for the safe use of

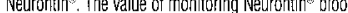

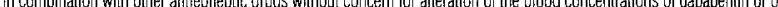
other anterileptic drugs. Orug interactions Gabapentin is nol aporeciadly metabolized nor does it interere with the metabolism of commonly coadministered antiepileptic druas. The drug interaction data described in this section were obtained "rom studles involving healthy acults and aoult calients with ep eosy. Phenytoin: In a single and mutipie cose study of Neurontin $440 . \mathrm{mg}$ T.I. D. in epileptic patienis $(\mathrm{N}=8)$ maintained on phenytoin monotheraoy tor at least 2 months gabapentin had no effect on the steady-state trough plasma concentrations of phenytoin and phenytoin had no effect on aabapentin pharmacokinetics. Carbamazepine: Steady-state trough olasma carbamazepine and carbanazepine 10 11 epoxide concentrations were not atected by conconitant gabapentin ( 400 mig T.I.D.; $N=12$ ) adrininstration. Likewise,

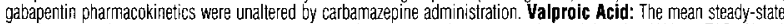

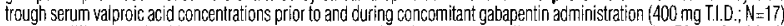
were not different and nether were gacapentin pharmacokinetic parameters affected by valproic acid. Phenobarbital: Estimates of steady-state pharmacokinetic parameters for phenobarb: tal or gabapentin (300 $\mathrm{mg} \mathrm{T.I.} . \mathrm{D}$; : $\mathrm{N}=12$ ) are identical whether the drugs are administered alone or together. Cimetidine: In the presence of cimetidine at $300 \mathrm{mg} Q .1 .0$. (N=12) the mean apparent oral clearance of gabapentin fell by $14 \%$ and creatinine clearance fell by $10 \%$. Thus cimetidine appeared to atter the renal excretion of both gabapentin and creatinine, an endogenous marker of renal function. This small decrease in excretion of gabapentin by cimetidine is not expected to be of clinical importance. The effect of gabapentin on cimetidine was not evaluated. Oral Contraceptive: Based on AUC and half-life, multiple-dose pharmacokinetic protiles of norethindrone and ethinyl estradiol tollowing administration of tablets containing $2.5 \mathrm{mg}$ of norethindrone acetate and $50 \mathrm{mcg}$ of ethinyl estradiol were similar with and without coadministration of gabapentin ( $400 \mathrm{mg}$ T.I.D. . N=13). The Cmax of norethindrone was $13 \%$ higher when it was coadministered wilh gabapentin: this interaction is not expected to be of clinical importance. Antacid (Maalox ${ }^{\text {B }}$ ): Maalox reduced the bioavailability of gabapentin $(\mathrm{N}=16)$ by about $20 \%$. This decrease in bicavailability was about $5 \%$ when gabapentin was administered 2 hours ater Maalox. It is recommended that gabapentin be taken at least 2 hours following Maalox administration. Effect of Probenecid: Probenecid is a blocker of renal tubular secretion. Gabapentin pharmacokinetic parameters without and with probenecid were comparable. This indicates that gabapentin does not undergo renal tubular secretion by the pathway that is blocked by probenecid. Drug/Laboratory Tests Interactions Because lalse positive readings were reported with the Ames N-Multistix SG dipstick test for urinary protein when gabapentin was added to other antiep;leptic drugs, the more specific sulffosalicy ic acid precipitation procedure is recommended to determine the presence of urine protein. Carcinogenesis, Mutagenasis, Impairment of fertility Gabapentin was given in the diet to mice at 200,600 , and $2000 \mathrm{mg} / \mathrm{kg} / \mathrm{day}$ and to rats at 250 1000 , and $2000 \mathrm{mg} / \mathrm{kg} / \mathrm{day}$ for 2 years. A statistically significant increase in the incidence of pancreatic acinar cell adenomas and carcinomas was found in male rats receiving the high dose; the no-effect dose for the occurrence of carcinomas was 1000 mokg/day. Peak plasma concentrations of gabapentin in rats receiving the high dose of $2000 \mathrm{mg} / \mathrm{kg}$ were 10 times

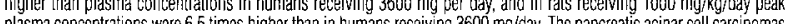
did

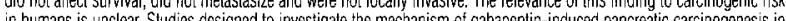
n indis in rats ind cate that gabapentin stimulas. tumor prom in by ence

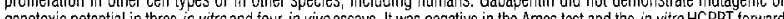
gentalon assa in Chirese ham in itro assay in che nicro chine has in mictronctions not induce cose 0 a

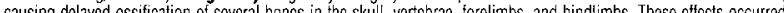
1 to pregnant mice received ora: doses of 1000 or $3000 \mathrm{mg} / \mathrm{kg} / \mathrm{day}$ dun 1 to 4 times ine maximum cose of $3600 \mathrm{mg} / \mathrm{day}$ given to eplep.c palis $500 \mathrm{mg} / \mathrm{kg} / \mathrm{day}$ or approximately $1 / 2$ of the human dose on a mg/m² basis. When rats were dosed prior to and during mating.

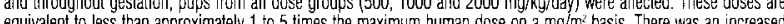
equivalent lo less han ap poximaty 1 to 5 thes he maximum human cose on a mg/ $\mathrm{m}^{2}$ basis. There was an increased incidence ol ind with

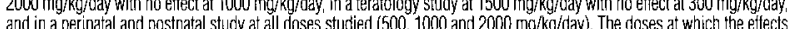
and in a pern.al and posha:al stdy at the occurred are approximately 105 times hie maximum human dose of $3600 \mathrm{mg} / \mathrm{day}$ on a mg/m bas $1 \mathrm{~s}$; the no-eftect doses were approximately 3 times (Fertility and General Reproductive Pertormanice study) and approximately equal to (Teratogenicity study) the maximum human oose on a $\mathrm{mg} / \mathrm{m}^{2}$ basis. Other than hydroureter and hydronephrosis, the etiologies of which are unclear, the incidence of malformations was not increased compared to controls in offspring dose on a mg/kg basis, or 4 times (mice), 5 times (rats), or 8 times (rabbits) the human daily dose on a mo/m' basis. 


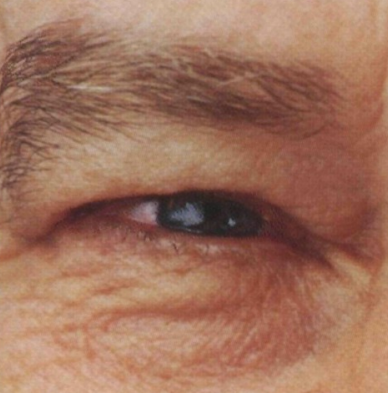

HE'S THE
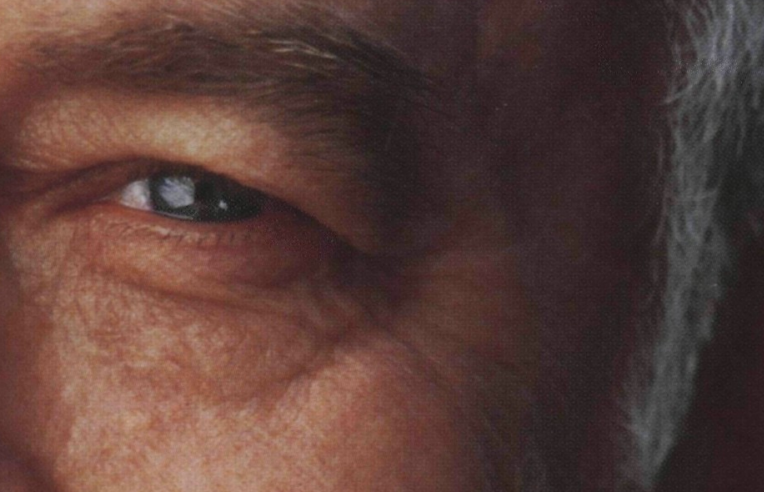


\title{
STRONG SILENT TYPE.
}

\section{LIKE HIS NEURONTIN.}

\section{ADD-ON PARTIAL-SEIZURE CONTROL WITH EXCELLENT TOLERABILITY}

\author{
Efficacy in a range of patients \\ Well tolerated \\ Effective starting dose \\ Rapid titration to maximum efficacy \\ Simple, safe pharmacokinetics
}

Available in 100-mg, 300-mg, and 400-mg capsules, $600-\mathrm{mg}$ and $800-\mathrm{mg}$ tablets, and an oral solution

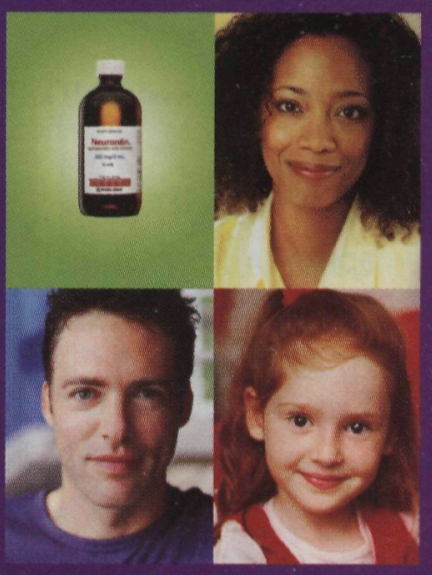

NEURONTIN is indicated as adjunctive treatment for partial seizures in pediatric patients (3-12 years old) and for partial seizures with and without secondary generalization in adults ( $>12$ years old). NEURONTIN is contraindicated in patients who have demonstrated hypersensitivity to the drug or its ingredients. NEURONTIN use in pediatric patients aged 3 to 12 years has been associated with mild to moderate neuropsychiatric adverse events, including emotional lability, hostility, thought disorder, and hyperkinesia.

In controlled clinical trials, the most common adverse events reported with NEURONTIN vs placebo in adults ( $>12$ years old) were somnolence ( $19.3 \%$ vs $8.7 \%$ ), dizziness ( $17.1 \%$ vs $6.9 \%)$, ataxia (12.5\% vs $5.6 \%)$, fatigue ( $11.0 \%$ vs $5.0 \%)$, and nystagmus $(8.3 \%$ vs $4.0 \%$ ); the most common adverse events in pediatric patients ( $3-12$ years old) were viral infection $(10.9 \%$ vs $3.1 \%)$, fever $(10.1 \%$ vs $3.1 \%)$, nausea and/or vomiting (8.4\% vs $7.0 \%)$, somnolence ( $8.4 \%$ vs $4.7 \%)$, and hostility $(7.6 \%$ vs $2.3 \%)$. 


\section{CNS SPECTRUMS}

The International Journal of Neuropsychiatric Medicine

\section{EDITOR}

Jack M. Gorman, MD

College of Physicians and

Surgeons, Columbia University

New York, NY

\section{INTERNATIONAL EDITOR}

Joseph Zohar, MD

Chaim Sheba Medical Center

Tel Hashomer, Israel

\section{ASSOCIATE INTERNATIONAL EDITORS \\ EUROPE}

Donatella Marazziti, MD

University of Pisa

Pisa, Italy

\section{MID-ATLANTIC}

Dan J. Stein, MB

University of Stellenbosch

Tygerberg, South Africa

\section{FAR EAST}

Shigeto Yamawaki, MD, PhD

Hiroshima University School

of Medicine

Hiroshima, Japan

\section{EDITORIAL DIRECTOR}

James M. La Rossa Jr.

FOUNDING EDITOR

Eric Hollander, MD

\section{BOARD OF ADVISORS}

Margaret Altemus, MD

Cornell University Medical Center New York, NY

Mitchell F. Brin, MD

Mount Sinai School of Medicine New York, NY

Dennis S. Charney, MD

Yale University

New Haven, CT

Jeffrey L. Cummings, MD

University of California Los Angeles, CA

Dwight L. Evans, MD

University of Pennsylvania

Philadelphia, PA

Mark George, MD

Medical University of South Carolina Charleston, SC

Thomas R. Insel, MD

Yerkes Primate Labs

Emory University School of Medicine Atlanta, GA

Lorrin M. Koran, MD

Stanford University Medical School Stanford, CA

Herbert Y. Meltzer, MD

Vanderbilt University Medical Center Nashville, TN

Stuart A. Montgomery, MD

St. Mary's Hospital Medical School London, United Kingdom

Dennis L. Murphy, MD

National Institute of Mental Health Bethesda, MD
Charles B. Nemeroff, MD, PhD

Emory University School of Medicine Atlanta, GA

Humberto Nicolini, MD, PhD

Instituto Mexicano de Psiquiatria Mexico City, Mexico

Katharine Phillips, MD

Brown University

Providence, RI

Harold A. Pincus, MD

Western Psychiatric Institute \& Clinic Pittsburgh, PA

Scott L. Rauch, MD

Massachusetts General Hospital Charlestown, MA

Alan Schatzberg, MD

Stanford University Medical School Stanford, CA

Norman Sussman, MD

New York University Medical School New York, NY

Neal R. Swerdlow, MD, PhD

University of California, San Diego

La Jolla, CA

Michael Trimble, MD

National Hospital for Neurology

and Neurosurgery

London, United Kingdom

Herman G.M. Westenberg, MD

University Hospital Utrecht

Utrecht, The Netherlands

Stuart Yudofsky, MD

Baylor College of Medicine

Houston, TX
MEDWORKS MEDIA Corporate Staff

\section{VICE PRESIDENTS AND}

ASSOCIATE PUBLISHERS

Imre Balanli

Genevieve Romano

MANAGING EDITOR

Edward Petoniak

SENIOR EDITOR

Christopher Naccari

SENIOR EDITOR, INTERNATIONAL

Amanda Schoenberg

DEPUTY EDITORS

Deborah Hughes

José R. Ralat

CME PROJECTS EDITOR

Kadrin Wilfong

SENIOR ACQUISITIONS EDITOR

Caroline Carlin Risman

ACQUISITIONS EDITOR

Lisa Arrington

\section{ART DIRECTION \& DESIGN}

Anthony J. Korsak

PRODUCTION COORDINATOR

Lila Moses

ASSISTANT TO THE PUBLISHER

Lowell Yaeger

DESIGNER, MULTIMEDIA

Michael Mosley

\section{ADMINISTRATIVE ASSISTANT}

Claudette Crawford

CORPORATION COUNSEL

Kevin F. Saer, Esq.

Davis, Wright \& Tremaine

DIRECTOR OF ADVERTISING SALES

Darren L. Brodeur

MARKETING DIRECTOR, GLOBAL

James Kassaris

PUBLISHER \& FOUNDER

James M. La Rossa Jr. 


\section{Comith Soon}

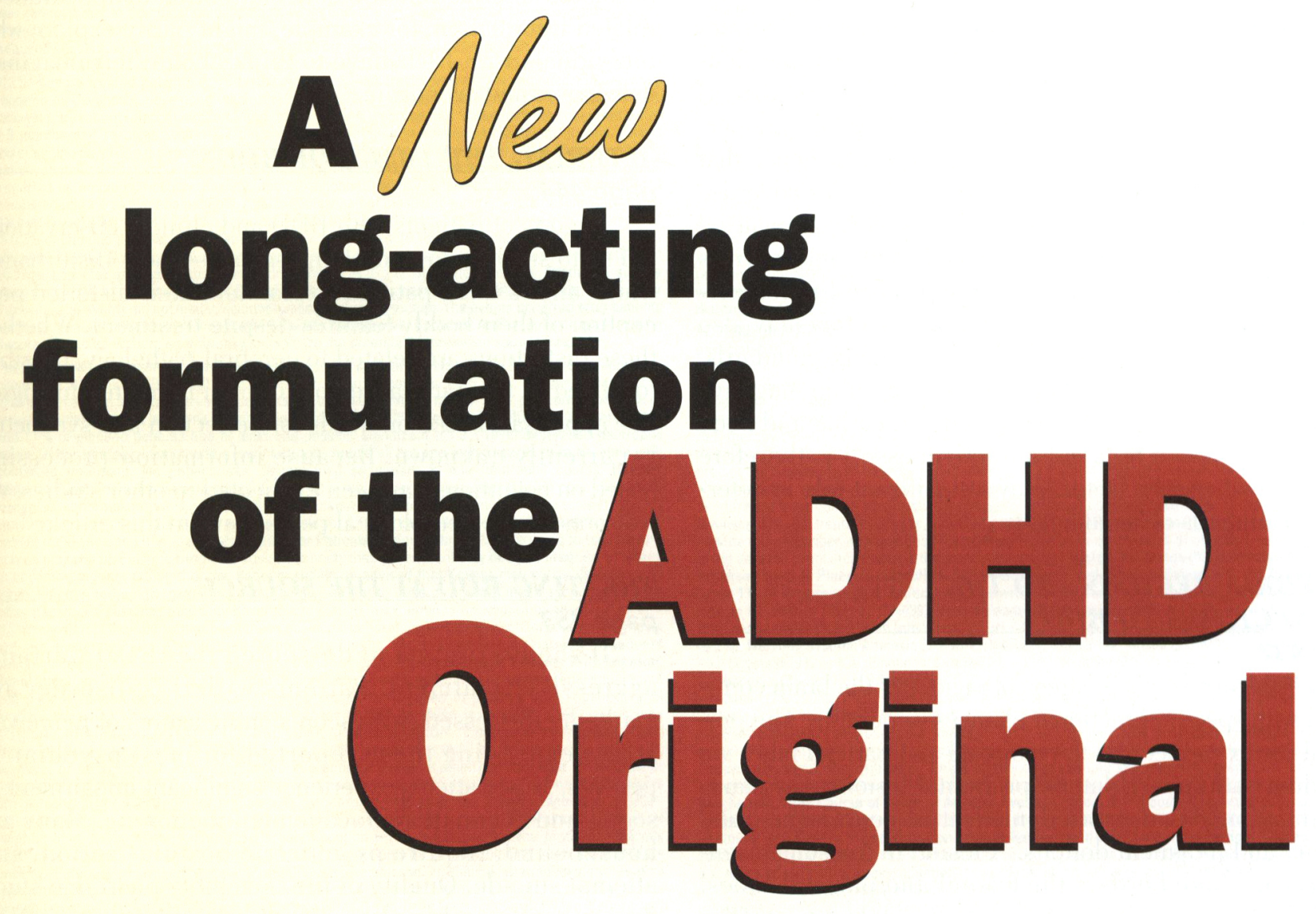

\section{(1) NOVARTIS}

Novartis Pharmaceuticals Corporation 


\section{CNS Digest \\ In the Journal of June 2002}

\section{BIOLOGICAL DETERMINISM AND BDD} page 429

"The sizes of secondary sexual facial characteristics that develop during puberty are also important in ratings of attractiveness. Enlarged jaws, chins, and cheekbone are examples of secondary sexual traits that are enlarged by testosterone during puberty in men. The largeness of these features are considered by women as sexually attractive, perhaps because they advertise a strong immune system. Female attractiveness is correlated with the opposite-tiny lower faces, big lips, and a slender lower jaw. Rhodes and colleagues found that exaggerated female traits were attractive in both female faces and male faces, corroborating similar findings by Perrett and colleagues. The results of Rhodes and colleagues and Perrett and colleagues are particularly significant because there is stronger evidence that the sizes of secondary sexual facial characteristics advertise health and immunocomptence in males more than females. ${ }^{14}$ The research presented so far to define facial beauty derives from a biological perspective. There is some limited evidence indicating that social and cultural factors may also play important roles in influencing body-image standards. However, the research to date has focused on the negative impact media exposure has on disordered eating and body weight, as opposed to facial attractiveness. It is therefore unclear whether such factors play a significant role in determining standards of facial beauty."

\section{CEREBRAL REGIONS AND THE CONNECTIONS TO BDD \\ page 432}

"Lesions in specific anatomical regions of the brain correspond with specific functional changes or deficits. The prefrontal cortex connects to the temporal and parietal lobes via cingulum pathways. Bilateral prefrontal lesions may cause concentration loss, decreased intellectual performance, and memory and judgment deficits. A lesion in the somatosensory area, which borders the frontal and parietal lobes, causes loss of perception or reception. Parietal lobe activities include interpretation and integration of information from sensory areas (ie, somatosensory and visual cortex). Consequently, parietal lesions cause sensory ataxia, general awareness loss, apathy, faulty sensory impulse recognition, and inability to interpret spatial relationships. Lesions in one side of the striate cortex, or primary visual area, cause contralateral hemianopsia, while lesions in the secondary visual area result in an inability to interpret visual impulses. The temporal lobes receive and interpret auditory information, pattern recognition, and higher visual coordination. The temporal lobe interconnections manage highly integrated activity. Lesions in this region modify normal behaviors and cause misperceptions (ie, hallucinations) and seizures. These anatomicofunctional correlations are summarized in the Table."

\section{HOW EMOTIONS AND RESPONSE ALTER OUR IMAGE page 435}

"Patients with anxiety disorders and individuals with high trait anxiety tend to selectively process threatening information, a bias that might contribute to the development or maintenance of emotional disorders. Investigating attentional processes in BDD, we found that individuals with $\mathrm{BDD}$, in contrast to healthy controls, selectively attended to appearance-related information and emotional appearanceunrelated information. ${ }^{8}$ Selective attention to appearancerelated information, for example, might partly explain why individuals with BDD have to think about their imagined defect over and over again."

\section{ALTERING THE IMAGE OF BDD \\ page 444}

"Reports of patients with BDD and clinical observations led us to suspect an underlying somatosensory disturbance which allows these patients to maintain their distorted perception of their bodily features despite treatment. Whether these distortions are related to cerebral pathology, possibly localized in the parietal region, or merely related to cognitive appraisals based on needs for perfection and symmetry, is currently unknown. Because information-processing based on cognitions has been explicated in other studies, we will present the neurological perspective in this article."

\section{TREATING BDD AT THE SOURCE page $\mathbf{4 5 3}$}

"It should first be underscored that BDD warrants aggressive treatment. Patients with this disorder are markedly distressed, with scores on measures of perceived stress exceeding those reported for most psychiatric patients. Most patients experience significant impairment in social and occupational/academic functioning. Many are housebound, require psychiatric hospitalization, and attempt suicide. Quality of life is notably poor: one study found that mental health-related quality of life for BDD patients was poorer than for the United States' population as a whole as well as for patients with depression or a chronic or acute medical condition (eg, diabetes or acute myocardial infarction). Furthermore, although it is relatively common, BDD usually goes undiagnosed in clinical settings."

\section{THERAPEUTIC APPROACHES TO BDD page 464}

"One of the first, if not the very first, case using behavioral treatment was reported by Munjack in 1978. A 27 year-old male preoccupied with an overly red complexion was treated using systematic desensitization in 11 sessions. The patient was taught relaxation training and a hierarchy of feared or avoided situations was constructed. Munjack concluded that behavior therapy may be successful for those patients sensitive to criticism whose complaints have a phobic quality." 
KEPPRA ${ }^{\star}$ (levetiracetam)

$250 \mathrm{mg}, 500 \mathrm{mg}$ and $750 \mathrm{mg}$ tablets

BRIEF SUMMARY (for full prescribing information, consult package insert)

Re only

INDICATIONS AND USAGE: Keppra (levetiracetam) is indicated as adjunctive therapy in the treatment of partial onset seizures in adults with epilepsy.

CONTRAINDICATIONS: This product should not be administered to patients who have previously exhibited hypersensitivity to levetiracetam or any of the inactive ingredients in Keppra tablets.

WARNINGS: Neuropsychiatric Adverse Events: Keppra use is associated with the occurrence of central nervous system adverse events that can be classified into the following categories: 1) somnolence and fatigue, 2) coordination difficulties, and 3) behavioral abnormalities. In controlled trials of patients with epilepsy, $14.8 \%$ of Keppra treated patients reported somnolence, compared to $8.4 \%$ of placebo patients. There was no clear dose response up to $3000 \mathrm{mg} / \mathrm{day}$. In a study where there was no titration, about $45 \%$ of patients receiving $4000 \mathrm{mg} /$ day reported somnolence. The somnolence was considered serious in $0.3 \%$ of the treated patients, compared to $0 \%$ in the placebo group. About $3 \%$ of Keppra treated patients discontinued treatment due to somnolence, compared to $0.7 \%$ of placebo patients. In $1.4 \%$ of treated patients and in $0.9 \%$ of placebo patients the dose was reduced, while $0.3 \%$ of the treated patients were reported asthenia, compared to $9.1 \%$ of placebo patients. Treatment was discontinued in $0.8 \%$ of treated patients as compared to $0.5 \%$ of placebo patients. In $0.5 \%$ of treated patients and in $0.2 \%$ of placebo patients the dose was reduced. A total of $3.4 \%$ of Keppra treated patients experienced coordination difficulties (reported as either. patients. A total of $0.4 \%$ of patients in controlled trials discontinued Keppra treatment due to ataxia, patients. A total of $0.4 \%$ of patients in controlled trials discontinued Keppra treatment due to ataxia, was reduced due to coordination difficulties, while one of the treated patients was hospitalized due to worsening of preexisting ataxia. Somnolence, asthenia and coordination difficulties occurred mos frequently within the first 4 weeks of treatment. In controlled trials of patients with epilepsy, $5(0.7 \%)$ of Keppra treated patients experienced psychotic symptoms compared to $1(0.2 \%)$ placebo patient. Two reported as psychosis, developed within the first week of treatment and resolved within 1 to 2 weeks following treatment discontinuation. Two other events, reported as hallucinations, occurred after 1-5 months and resolved within 2-7 days while the patients remained on treatment. In one patient experiencing psychotic depression occurring within a month, symptoms resolved within 45 days while the patient continued treatment. A total of $13.3 \%$ of Keppra patients experienced other behavioral symptoms (reported as agitation, hostility, anxiety, apathy, emotional lability, depersonalization, depression, etc.) compared to $6.2 \%$ of placebo patients. Approximately half of these patients reported these events within the first 4 weeks. A total of $1.7 \%$ of treated patients discontinued treatment due to these events, compare placebo patients. A total of $0.8 \%$ of treated patients had a serious behavioral event (compared to $0.2 \%$ placebo patients and were hospitalized In addition $410.5 \%$ of treated patients attempted suicide Thy committed suicide. In the other had been treated for between 4 weeks and 6 months. Withdrawal Seizures: Antiepileptic drugs, including Keppra, should be withdrawn gradually to minimize the potential of increased seizure frequency.

PRECAUTIONS: Hematologic Abnormalities: Minor, but statistically significant, decreases compared to placebo in total mean RBC count $\left(0.03 \times 10 \% \mathrm{~mm}^{2}\right\rangle$, mean hemoglobin $\{0.09 \mathrm{~g} / \mathrm{dL}$, and mean hematocrit placebo patients had at least one possibly significant $(\leq 2.8 \times 10 \% \mathrm{~L})$ decreased WBC, and $2.4 \%$ of treated and $1.4 \%$ of placebo patients had at least one possibly significant $\left(\leq 1.0 \times 10^{9} / L\right)$ decreased neutrophil count, Of the treated patients with a low neutrophil count, all but one rose towards or to baseline with Abnormalities: There were no meaningful changes in mean liver function tests (LFT) in controlled trials: lesser LFT abnormalities were similar in drug and placebo treated patients in controlied trials $(1.4 \%)$. No patients were discontinued from controlled trials for LFT abnormalities except for $1(0.07 \%)$ epilepsy patient receiving open treatment. Information For Patients: Patients should be instructed to take Keppra patient receiving open treatment. Information For Patients: Patients should be instructed to take Keppra only as prescribed. Patients should be advised to notify their physician if they become pregnant or intend to become pregnant during therapy. Patients should be advised that Keppra may cause dizziness and
somnolence. Accordingly, patients should be advised not to drive or operate machinery or engage in other hazardous activities until they have gained sufficient experience on Keppra to gauge whether it adversely affects their performance of these activities. Laboratory Tests: Although most laboratory test are not systematically altered with Keppra treatment, there have been relatively infrequen abnormalities seen in hematologic parameters and liver function tests. Use in Patients With Impaire Renal Function: Caution should be taken in dosing patients with moderate and severe renal impairment and patients undergoing hemodialysis. Dosage should be reduced in patients with impaired renal function receiving Keppra and supplemental doses should be given to patients after dialysis (see CLINICAL PHARMACOLOGY and DOSAGE AND ADMINISTRATION, Patients with Impaired Renal Function). Drug Interactions: in vitro data on metabolic interactions indicate that Keppra is unlikely to produce, or be subject to, pharmacokinetic interactions. Levetiracetam and its major metabolite, at of nor high affinity substrates for human liver within the therapeutic dose range, are neither inhibitor glucuronidation enzymes. In addition, levetiracetam does not affect the in vitro glucuronidation of valproic acid. Levetiracetam circulates largely unbound $(<10 \%$ bound) to plasma proteins; clinically significant interactions with other drugs through competition for protein binding sites are therefore unlikely. Potential pharmacokinetic interactions were assessed in clinical pharmacokinetic studies unlikely. Potential pharmacokinetic interactions were assessed in clinical pharmacokinetic studies (phenytoin, warfarin, digoxin, oral contraceptive) and through pharmacokinetic screening in the
placebo-controlled clinical studies in epilepsy patients. Drug-Drug Interactions Between Keppra and placebo-controlled clinical studies in epilepsy patients. Drug-Drug Interactions Between Keppra and
Existing Antiopileptic Drugs (AEDs): Potential drug interactions between Keppra and existing AEDs Existing Antiopileptic Drugs (AEDs): Potential drug interactions between Keppra and existing AEDs (phenvoin, carbamazepine, valproic acid, phenobarbital, lamotrigine, gabapentin and primidone) were controlled clinical studies. These data indicate that levetiracetam does not influence the plasma controlled clinical studies. These data indicate that levetiracetam does not influence the plasma concentration of existing AEDs and that these AEDs do not influence the pharmacokinetics of
levetiracetam. Other Drug Interactions: Oral Contraceptives: Keppra $(500 \mathrm{mg}$ twice daily) did not levetiracetam. Other Drug Interactions: Oral Contraceptives: Keppra (500 mg twice daily) did not levonorgestrel, or of the luteinizing hormone and progesterone levels, indicating that impairment contraceptive efficacy is unlikely. Coadministration of this oral contraceptive did not influence th pharmacokinetics of levetiracetam. Digoxin: Keppra (1000 $\mathrm{mg}$ twice daily) did not influence the pharmacokinetics and pharmacodynamics (ECG) of digoxin given as a $0.25 \mathrm{mg}$ dose every day Coadministration of digoxin did not influence the pharmacokinetics of levetiracetam. Warfarin: Keppra $(1000 \mathrm{mg}$ twice daily) did not influence the pharmacokinetics of $R$ and $S$ warfarin. Prothrombin time was not affected by levetiracetam. Coadministration of warfarin did not affect the pharmacokinetics of of $500 \mathrm{mg}$. Probenecid: Probenecid, a renal tubular secretion blocking agent, administered at a dos $C^{30}$ of fraction of drug excreted unchanged in the urine remained the same. Renal clearance of ucb L057 in the presence of probenecid decreased $60 \%$, probably related to competitive inhibition of tubular secretion presence of probenecid decreased $60 \%$, probably related to competitive inhibition of tubular secretion
of ucb L057. The effect of Keppra on probenecid was not studied. Carcinogenesis, Mutagenesis. of ucb L057. The effect of Keppra on probenecid was not studied. Carcinogenesis, Mutagenesis, doses of 50,300 and $1800 \mathrm{mg} / \mathrm{kg} / \mathrm{day}$. The highest dose corresponds to 6 times the maximum recommended daily human dose (MRHD) of $3000 \mathrm{mg}$ on a mg/m $/ \mathrm{m}^{2}$ basis and it also provided systemic recommended daily human dose (MRHD) of $3000 \mathrm{mg}$ on a mg/m $/ \mathrm{m}^{2}$ basis and it also provided systemic exposure (AUC) approximately 6 times that achieved in humans receiving the MRHD. There was no
evidence of carcinogenicity. A study was conducted in which mice received levetiracetam in the diet for evidence of carcinogenicity. A study was conducted in which mice received levetiracetam in the diet for
80 weeks at doses of 60,240 and $960 \mathrm{mg} / \mathrm{kg} /$ day high dose is equivalent to 2 times the MRHD on a mg/m or exposure basis). Although no evidence for carcinogenicity was seen, the potential for a carcinogenic response has not been fully evaluated in that species because adequate doses have not been studied. Mutagenesis: Levetiracetam was not mutagenic in the Ames test or in mammalian cells in vitro in the Chinese hamster ovary/HGPRT locus assay. It was not clastogenic in an in vitro analysis of metaphase chromosomes obtained from Chinese hamster ovary cells or in an in vivo mouse micronucleus assay. the Ames test or the in vitro mouse lymphoma assay. Impairment of Fertility No adverse effects on male to lapproximately 6 times the maximum recommended human dose on a $\mathrm{mg} / \mathrm{m}^{2}$ or exposure basis. Pregnancy: Pregnancy Category C: In animal studies, levetiracetam produced evidence developmental toxicity at doses similar to or greater than human therapeutic doses. Administration to female rats throughout pregnancy and lactation was associated with increased incidences of mine fetal skeletal abnormalities and retarded offspring growth pre-and/or postnatally at doses $\geq 350 \mathrm{mg} / \mathrm{kg} /$ day (approximately equivalent to the maximum recommended human dose of $3000 \mathrm{mg}$ [MRHD] on a $\mathrm{mg} / \mathrm{m}^{2}$ basis) and with increased pup mortality and offspring behavioral alterations at a dose of $1800 \mathrm{mg} / \mathrm{kg} /$ day (6 times the MRHD on a $\mathrm{mg} / \mathrm{m}^{2}$ basis). The developmental no effect dose was $70 \mathrm{mg} / \mathrm{kg} / \mathrm{day}(0.2$ times the MRHD on a mg/m² basis). There was no overt maternal toxicity at the doses used in this study. Treatment of pregnant rabbits during the period of organogenesis resulted in increased embryofetal mortality and increased incidences of minor fetal skeletal abnormalities at doses increased incidences of fetal malformations at a dose of $1800 \mathrm{mg} / \mathrm{kg} /$ day $(12 \mathrm{times}$ the MRHD on a mg/m Maternal toxicity was also observed at $1800 \mathrm{mg} / \mathrm{kg} /$ day. When pregnant rats were treated during the period of organogenesis, fetal weights were decreased and the incidence of fetal skeletal variation was increased at a dose of $3600 \mathrm{mg} / \mathrm{kg} /$ day (12 times the MRHD). $1200 \mathrm{mg} / \mathrm{kg} /$ day $(4$ times the MRHD) was a developmental no effect dose. There was no evidence of maternal toxicity in this study. Treatment of rats during the last third of gestation and throughout lactation produced no adverse developmental or of rats during the last third of gestation and throughout lactation produced no adverse developmental or
maternal effects at doses of up to $1800 \mathrm{mg} / \mathrm{kg} / \mathrm{day}\left(6\right.$ times the MRHD on a $\mathrm{mg} / \mathrm{m}^{2}$ basis). There are no madequate and well-controlled studies in pregnant women. Keppra should be used during pregnancy only if the potential benefit justifies the potential risk to the fetus. Pregnency Exposure Registry: To facilitate monitoring fetal outcomes of pregnant women exposed to Keppra physicians are encouraged to register patients, before fetal outcome is known (e.g., ultrasound, results of amniocentesis, etc.), in the
Antiepileptic Drug Pregnancy Registry by calling (888) 233-2334 (toll free). Labor and Delivery: The effect of Keppra on labor and delivery in humans is unknown. Nursing Mothers: It is not known whether this drug is excreted in human milk. Because many drugs are excreted in human milk, caution should b exercised when Keppra is administered to a nursing woman. Pediatric Use: Safety and effectiveness in patients below the age of 16 have not been established. Geriatric Use: Of the total number of subjects in clinical studies of levetiracetam, 347 were 65 and over. No overall differences in safety were observed between these subjects and younger subjects. There were insufficient numbers of elderly subjects in in 16 elderly subjects (age 61-88 years) with oral administration of single dose and multiple twice-daily doses for 10 days showed no pharmacokinetic differences related to age alone. Levetiracetam is known in patients with imp excreted by the kidney, and the risk of adverse reactions to this drug may be greate renal function, care should be taken in dose selection, and it may be useful to monitor renal function. Use in Patients With Impaired Renal function: Clearance of levetiracetam is decreased in patients with in Patients With impaired Renal function: Clearance of levetiracetam is decreased in patients with renal impairment and is correlated with creatinine clearance. The dosage should be reduced in patients dialysis (see DOSAGE AND ADMINISTRATION, Patients with Impaired Renal Function)

ADVERSE REACTIONS: In well-controlled clinical studies, the most frequently reported adverse events associated with the use of Keppra in combination with other $\mathrm{AED}$, not seen at an equivalent frequency among placebo-treated patients, were somnolence, asthenia, infection and dizziness. Table 1 lists Keppra participent adverse events that occurred in at least $1 \%$ of patients with epilepsy treated with treated with Keppra than placebo. In these studies, either Keppra or placebo was added to concurrent AED therapy. Adverse events were usually mild to moderate in intensity. The prescriber should be aware that these figures, obtained when Keppra was added to concurrent AED therapy, cannot be used to predict the frequency of adverse experiences in the course of usual medical practice where patient characteristics and other factors may differ from those prevailing during clinical studies. Similarly, the cited frequencies cannot be directly compared with figures obtained from other clinical investigations cited frequencies cannot be directly compared with figures obtained from other clinical investigations involving different treatments, uses, or investigators. An inspection of these frequencies, however, does to the adverse event incidences in the population studied. Table l: Incidence (\%) of Treatment-emergent to the adverse event incidences in the population studied. Table 1: Incidence (\%) of Treatment-emergent Adverse Events in Placebo-controlled, Add-on Studies by Body System (Adverse Events Occurred in at
Least 1\% of Keppra-treated Patients and Occurred More Frequently than Placebo-treated Patients) Keppra ( $N=769$ ) vs Placebo ( $N=439$ ): Body System/Adverse Event: Body as a Whole: Asthenia (15\% vs

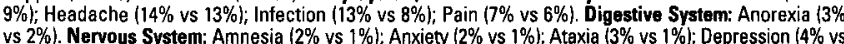

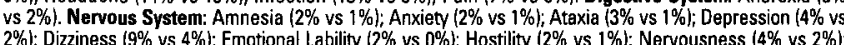
$2 \%)$; Dizziness (9\% vs $4 \%$ ); Emotional Lability $(2 \%$ vs $0 \%)$; Hostility $(2 \%$ vs $1 \%)$; Nervousness $(4 \%$ vs $2 \%)$,
Paresthesia ( $2 \%$ vs $1 \%$ ): Somnolence $(15 \%$ vs $8 \%)$ : Vertigo $(3 \%$ vs $1 \%)$. Respiratory System: Cough Paresthesia (2\% vs $1 \%)$; Somnolence (15\% vs $8 \%)$; Vertigo $(3 \%$ vs $1 \%)$. Respiratory System: Cough Diplopia ( $2 \%$ vs $1 \%$ ). Other events reported by $1 \%$ or more of patients treated with Keppra but as or mor frequent in the placebo group were: abdominal pain, accidental injury, amblyopia, arthralgia, back pain, bronchitis, chest pain, confusion, constipation, convulsion, diarrhea, drug level increased, dyspepsia, ecchymosis, fever, flu syndrome, fungal infection, gastroenteritis, gingivitis, grand mal convulsion, weight gain. Time Course of Onset of Adverse Events: Of the most frequently reported adverse events, asthenia, somnolence and dizziness appeared to occur predominantly during the first 4 weeks of treatment with Keppra. Discontinuation or Dose Reduction in Well-Controlled Clinical Studies: In welltreatment with Keppra. Discontinuation or Dose Reduction in Well-Controlled Clinical Studies: In wellcontrolled clinical studies, $15.0 \%$ of patients receiving Keppra and $11.6 \%$ receiving placebo either discontinued or had a dose reduction as a result of an adverse event. The adverse events most
commonly associated $(>1 \%)$ with discontinuation or dose reduction in either treatment group are presented in Table 2. Table 2: Adverse Events Most Commonly Associated With Discontinuation or Dose presented in Table 2. Table 2: Adverse Events Most Commonly Associated With Discontinuation or Dosa Reduction in Placebo-controlled Studies in Patients With Epilepsy Keppra ( $N=769)$ vs Placebo $(\mathrm{N}=439)$ :
[Number (\%)]: Asthenia $[10(1.3 \%)$ vs $3(0.7 \%)]$ : Convulsion $[23(3.0 \%)$ vs $15(3.4 \%)]$ Dizziness [11 (1.4\%) [Number (\%)]: Asthenia [10 $(1.3 \%)$ vs $3(0.7 \%)]$; Convulsion $[23(3.0 \%)$ vs $15(3.4 \%)]$; Dizziness [11 $(1.4 \%)$
vs 0]; Somnolence [34 $(4.4 \%)$ vs $7(1.6 \%)]$; Rash [0 vs $5(1.1 \%)]$. Comparison of Gender, Age and Race: The overall adverse experience profile of Keppra was similar between females and males. There are insufficient data to support a statement regarding the distribution of adverse experience reports by age and race.

DOSAGE AND ADMINISTRATION: Keppra is indicated as adjunctive treatment of partial onset seizures in adults with epilepsy. In clinical trials, daily doses of $1000 \mathrm{mg}, 2000 \mathrm{mg}$ and $3000 \mathrm{mg}$, given as twice a day dosing, were shown to be effective. Although in some studies there was a tendency toward greater response with higher dose (see CLINICAL STUDIES in package insert), a consistent increase in response with increased dose has not been shown. Treatment should be initiated with a daily dose of $1000 \mathrm{mg} /$ day, given as twice daily dosing $(500 \mathrm{mg}$ BID). Additional dosing increments may be given $(1000 \mathrm{mg} / \mathrm{day}$ additional every 2 weeks) to a maximum recommended daily dose of $3000 \mathrm{mg}$. Long term experience at doses greater than $3000 \mathrm{mg} /$ day is relatively minimal, and there is no evidence that doses greater than $3000 \mathrm{mg} /$ day confer additional benefit. Keppra is given orally with or without food. Patients With Impaired Renal Function: Keppra dosing must be individualized according to the patient's renal function status. Recommended doses and adjustment for dose are shown in the Table below. To use this dosing table, an
estimate of the patient's creatinine clearance (CLcr) in $\mathrm{mL} / \mathrm{min}$ is needed. CLcr in $\mathrm{mL} / \mathrm{min}$ may be estimated from serum creatinine $(\mathrm{mg} / \mathrm{dL})$ determination using the following formula:

$$
\mathrm{CLCr}=\frac{[140 \text {-age }(\text { years })] \times \text { weight }(\mathrm{kg})}{72 \times \text { serum creatinine }(\mathrm{mg} / \mathrm{dL})}(\times 0.85 \text { for female patients) }
$$

Dosing Adjustment Regimen for Patients With Impaired Renal Function

\begin{tabular}{lcll}
\hline Group & Creatinine Clearance $(\mathrm{mL} / \mathrm{min})$ & Dosage $(\mathrm{mg})$ & Frequency \\
\hline Normal & $>80$ & 500 to 1,500 & Every $12 \mathrm{~h}$ \\
Mild & $50-80$ & 500 to 1,000 & Every $12 \mathrm{~h}$ \\
Moderate & $30-50$ & 250 to 750 & Every $12 \mathrm{~h}$ \\
Severe & $<30$ & 250 to 500 & Every $12 \mathrm{~h}$ \\
ESRD patients using dialysis & - & 500 to 1,000 & Every $24 \mathrm{~h}$ \\
\hline
\end{tabular}

*Following dialysis, a 250 to $500 \mathrm{mg}$ supplemental dose is recommended. 


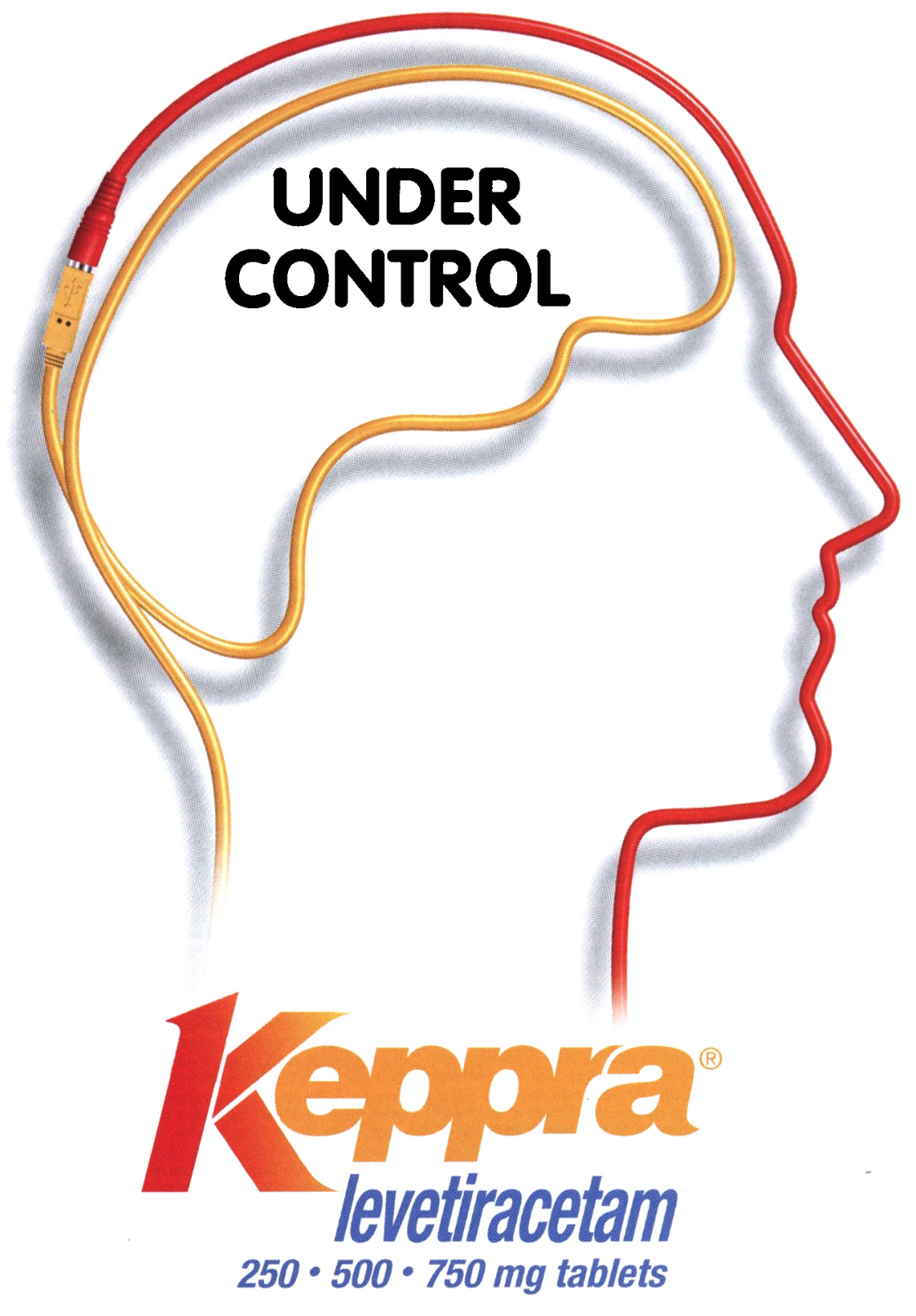

SIMPLIFYING SEIZURE CONTROL

PROVIDES UP TO 4 OUT OF 10 REFRACTORY PATIENTS WITH $\geq 50 \%$ PARTIAL ONSET SEIZURE REDUCTION

NO DRUG/DRUG INTERACTIONS WITH AEDS INCLUDED IN WELL-CONTROLLED STUDIES, A COMBINATION ORAL CONTRACEPTIVE, WARFARIN, OR DIGOXIN

GENERALLY WELL TOLERATED
Keppra® use is associated with the occurrence of central nervous system adverse events, classified as somnolence and fatigue, coordination difficulties, and behavioral abnormalities; and with minor, but statistically significant, hematological abnormalities. Keppra ${ }^{\oplus}$ dosing must be individualized according to renal function status. 


\section{Table of Contents}

Feature Articles

424 Introduction-Body Dysmorphic Disorder:

Conceptualization and Treatment

By Fugen Neziroglu, PhD, ABBP, ABPP

\section{REVIEW}

429 The Importance of Aesthetics in

Body Dysmorphic Disorder

By David M. Veale, MD, MRCPsych, and Christina Lambrou, BSC

\section{REVIEW}

432 Neuroanatomical Correlates and

Somatosensorial Disturbances in

Body Dysmorphic Disorder

By José A. Yaryura-Tobias, MD, Fugen Neziroglu, PhD, and Melissa Torres-Gallegos, MA

\section{ORIGINAL RESEARCH}

435 Interpretive Biases for Ambiguous

Information in Body Dysmorphic Disorder

By Ulrike Buhlmann, MS, Sabine Wilhelm, PhD,

Richard J. McNally, PhD, Brunna Tuschen-Caffier, PhD,

Lee Baer, PhD, and Michael A. Jenike, MD

\section{ORIGINAL RESEARCH}

444 Computerized Perceptual Analysis

of Patients with Body Dysmorphic Disorder

By José A. Yaryura-Tobias, MD, Fugen Neziroglu, PhD,

Robert Chang, MA, Sean Lee, Anthony Pinto, MA,

and Laura Donohue

\section{REVIEW}

453 Pharmacologic Treatment of Body Dysmorphic Disorder:

Review of the Evidence and a Recommended Treatment Approach

By Katherine A. Phillips, MD

\section{REVIEW}

464 A Review of Cognitive and Behavioral

Treatment for Body Dysmorphic Disorder

By Fugen Neziroglu, PhD, and Sony Khemlani-Patel, PhD

\begin{tabular}{c}
\hline CNS SPECTRUMS \\
\hline The International \\
Journal of \\
Neuropsychiatric \\
Medicine \\
volume $7 \cdot$ Number 6 \\
June 2002 \\
\hline
\end{tabular}

CNS Spectrums is a peer review journal and is indexed in EMBASE/Excerpta Medica, DIALOG, SilverPlatter, OVID, and Lexis-Nexis. CNS Spectrums is endorsed by, and is the official journal of, the International Neuropsychiatric Assoc., with members in 30 countries.

\section{CNS Spectrums}

(ISSN 1092-8529)

is published by

MedWorks Media,

333 Hudson Street, 7th Floor

New York, NY 10013.

One year subscription rates:

domestic \$120;

foreign $\$ 185$.

in-training $\$ 75$.

For subscriptions:

Fax: 212-328-0600

or visit our Web site

www.medworksmedia.com

Postmaster:

Send address changes to CNS Spectrums

clo PPS Medical Marketing Group 264 Passaic Ave.

Fairfield, NJ 07004-2595 


\section{$\overline{\text { CNS SPECTRUMS }}$}

The International Journal of

Neuropsychiatric Medicine

Volume $7 \cdot$ Number 6 June 2002

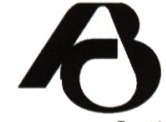

Audit Bureau of Circulations

MEMBER SINCE 20001

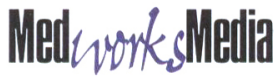

CNS Reviews ${ }^{\mathrm{TM}}$

CNS Spectrums ${ }^{\circledast}$

Mental Fitness ${ }^{\circledast}$

Oncology Spectrums ${ }^{\mathrm{TM}}$

Psiquiatría y Salud Integra/ $T^{\mathrm{M}}$

Psychopharmacology Bulletin ${ }^{\mathrm{TM}}$

TEN-Trends in Evidence-Based Neuropsychiatry ${ }^{\oplus}$

\section{Table of Contents}

Departments/MonthIy Colum ns

\section{Sea Horses and Almonds}

By Michael Trimble, MD, FRCP, FRPsych

Everyone knows the amygdalae and their location in the nervous system, or so it seemed until a few years ago. First called the amygdala by Burdach in 1819 because of their resemblance to almonds (Prunus amygdalus), the origin of today's discontent seems to have been laid down by J.B. Johnston, when in 1923 he described the amygdaloid complex.

\section{CNS NEWS}

422 Briefs From the Fields of Neurology \& Neuropsychiatry Study Tabs 'Modifiable' Risk Factors as Main Hemorrhagic Stroke Threats; Small Cohort Finds Program Effective in Combating Weight Gain Associated with Atypical Antipsychotics; Cause of Early Nerve Damage in Leprosy Linked to Peripheral Nervous System; Trial Finds Duloxetine Effective for Physical Symptoms of Depression; Request for Applications for Research on Research Integrity

\section{COnTINUING Medical edUCATION GradWORKS}

473 This Continuing Medical Education series gives the reader the opportunity to test his/her understanding and recall of clinical material presented in this issue. Approved for 3.0 credit hours in Category 1

\section{INDICES}

\section{By subject and author}

\section{ERRATUM}

The May 2002 issue of CNS Spectrums incorrectly listed on this page a Teaching Monograph titled "Pharmacologic Advances in the Treatment of ADHD." The monograph is slated to run in a future issue of CNS Spectrums.

For editorial and advertising inquiries, please fax 212-328-0600.

Opinions and views expressed by authors are their own and do not necessarily reflect the views of the publisher, MedWorks Media, or the editorial advisory board. Advertisements in CNS Spectrums are accepted on the basis of adherence to ethical medical standards, but acceptance does not imply endorsement by CNS Spectrums, or the publisher.

CNS Spectrums ${ }^{\circledR}$ is a registered trademark of CNS Spectrums, LLC, New York, NY.

CNS News ${ }^{\mathrm{TM}}$ is a trademark of MBL Communications, Inc., New York, NY.

Permission to reproduce articles in whole or part must be obtained in writing from the publisher.

Copyright $@ 2002$ by MedWorks Media. All rights reserved. Printed in the United States. 



\section{EXELON... The first choice that stays the course}

- Proven efficacy in global functioning, based on evaluation of 3 key domains of Alzheimer's disease... * Activities of daily living Behavior Gognition

- Dosing flexibility allows customized treatment ${ }^{1}$

- Simple 1-step dosing to therapeutic dosage range

- Clear dose response that can maximize efficacy

- Higher doses can be associated with increased incidence of adverse events, especially during dose titration

\section{Also available in oral solution}

Established safety profile

- Minimal metabolism by the CYP450 isoenzyme system'

- No clinically significant drug interactions in clinical trials'

- No dosage adjustment needed for patients with renal or hepatic impairment ${ }^{1}$

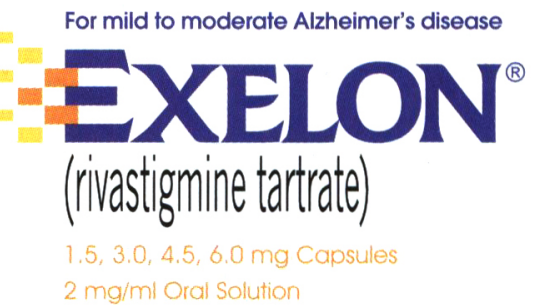

More than memories

Reference: 1. EXELON ${ }^{\circledR}$ [package insert]. East Hanover, NJ: Novartis Pharmaceuticals Corp; 2000

Please see brief summary of complete prescribing information on the next page.

In controlled clinical trials, the most common adverse events were nausea, vomiting, anorexia, dyspepsia, and asthenia. EXELON use is associated with significant gastrointestinal adverse reactions, including nausea and vomiting, anorexia, and weight loss. If therapy is interrupted for longer than several days, treatment should be reinitiated with the lowest daily dose in order to avoid the possibility of severe vomiting and its potentially serious sequelae. In the controlled trials, $47 \%$ of patients experienced nausea and $31 \%$ of patients experienced vomiting. Weight loss associated with EXELON occurred more commonly among women receiving high doses in clinical trials. Due to increased cholinergic activity, cholinesterase inhibitors may be expected to increase gastric acid secretion and/or have vagotonic effects on heart rate. Therefore, EXELON should be used with caution in patients with peptic ulcers, gastrointestinal bleeding, and "sick sinus syndrome" or other supraventricular cardiac conduction conditions. (Please see important WARNINGS in brief summary of full prescribing information.) 


\section{Exelon $^{\circledR}$}

\section{(rivastigmine tartrate)}

\section{Capsules}

Rx only

BRIEF SUMMARY: Ploase see package insort for full prescribing information.

MADIGATIONS AND USABE: Exelono (rivastigmine tartrate) is indicated for the treatment of mild to moderate dementia of the Alzheimer's type.

COWrRAMIMICATIOKS: Exelon (rivastigming tartrate) is contraindicated in patients with known hypersensitivity to rivastigmin WaAMMis: Gastrolntestinal Adverse Reactions: Exelon (rivastlgmine tartrate) use is assoclated with signifleant gastroIntestinal adverse reactlons, including nausea and vomiting, anorexla, and weight loss. For this reason, patients should always be started at a dose of $1.5 \mathrm{mg} 810$ and titrated to their maintenance dose. If treatment is interrupted for longer tull preseribing Information) to reduce the possibillty of severe vomitting and its potentlally serious sequelae (e.g., there
has been one post-marketling report of severe vomiting with esophageal rupture following inappropriate reinitiation of treatment with a $4.5-\mathrm{mg}$ dose after 8 wasks of treatment interruption).

Nausea and Vomiling: In the controlled cllnical trials. $47 \%$ of the patients traated with an Exelon dose in the therapeutic range of $6-12 \mathrm{mg} / \mathrm{day}$ ( $\mathrm{n=1189}$ ) dovelopod nausea (compared with $12 \%$ in placebo). A total of $31 \%$ of Exelon-treated
patients developed at ieast one opisode of vomlling (compared with $6 \%$ for placebol. The rate of vomiting was higher

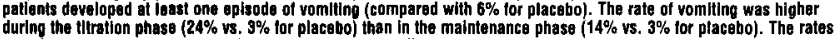

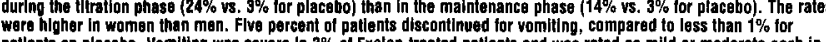
pallo on placebo. Vomiting was solvo por nance phase $(17 \%$ v8. $4 \%$ tor placebo $)$.

Woigh Loss: In the controlled trials, approximately $26 \%$ of women on high doses of Exelon (greater than $9 \mathrm{mg} / \mathrm{day}$ ) had welght loss of equal to or greater than $7 \%$ of their baselline walght compared to $6 \%$ in the placebo-treated patients. Abou patlents. It is not clear how much of the wolght loss was associated with anorexla, nausea, vomiting, and the diarrhea associated with the drut.

Anorexia: In the controlled clinical trials, of the patients treated with an Exelon dose of 6-12 mg/day, $17 \%$ developed anorexia compared to $3 \%$ of the placebo patients. Neither the time course or the severity of the anorexia is known.

Peptic UIcers/Gastrointestinal blooding: Because of their pharmacological action, cholinesterase inhibitors may be expected to increase gastric acid secretion due to increased cholinergic activity. Therefore, patients should be monitored closely for symptoms of active or occult gastrointestinal bleeding, especially those at increased risk for developing ulcers, e.g., those
with a history of ulcer disuase or those receiving concurrent nonsteroidal anti-inflammmatory drugs (NSAIDS). Clinical studies testinal bleeding.

Anesthesia: Exelon as a cholinesterase inhibitor, is likely to exaggerate succinylcholine-type muscle relaxation during anesthesia Cardlovascular Condtitions: Orugs that increase cholinergic activity may have vagotonic effects on heart rate (e.g., bradycarlar adverse events, heart rate or blood pressure changes, or ECG abnormalities. Sy
patients recelving $6-12$ mo/day of Exelon, compared to $2 \%$ of placebo patients.

Genltourinary: Although this was not observed in clinical trials of Exelon, drugs that increase cholinergic activity may cause urinary obstruction.

Neurological Condiflons: Seizures' Drugs that increase cholinergic activity are believed to have some potential for causing seizures. However, seizure activity also may be a manitestation of Alzheimer's Disease.

Pulmonary Conditions: Like other drugs that increase cholinergic activity, Exelon should be used with care in patients with history of asthma or obstructive pulmonary disease.

PRECAUTIOUS: Intormation for Patlents and Caregivers: Caregivers should be advised of the high incidence of nausea and vomiting associated with the use of the drug along with the possibility of anorexia and weight loss. Caregivers should be encouraged to monitor for these adverse events and inform the physician if they occur. It is critical to inform caregivers that in therapy has been inter

Drug-Drug Intoractlons: Effocf of Exolone (rivastigmine tartrate) on the Metabolism of other Drugs: Rivastigmine is primarily metabolized through hydrolysis by esterases. Minimal metabolism occurs via the major cytochrome P450 isoenzymes. Based on in vitro studies, no pharmacokinetic drug interactions with drugs metabolized by the following isoenzyme systems No pharmacokinetic interaction was observed between rivastigmine and digoxin, warfarin, diazepam, or fluoxetine in studies in

Effect of Other Drugs on the Molabollsm of Exelon: Drugs that induce or inhibit CYP450 metabolism are not expected to alter the metabolism of rivastigmine. Single dose pharmacokinetic studies demonstrated that the metab
significantly affected by concurrent administration of digoxin, warfarin, diazepam, or fluoxetine.

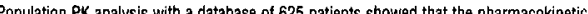
Population $P X$ analysis with a database of 625 patients showed that the pharmacokinetics of rivastigmine were not influence by $(n=177)$, antianginals $(n=35)$, and antihistamines $(n=15)$.

Use with Antichoflingrg/cs: Because of their mechanism of action, cholinesterase inhibitors have the potential to interfere with the activity of anticholinergic medications.

Use with Cholinomimettes and Other Cholinesterase Inthbltors: A synergistic effect may be expected when cholinesterase inhibitors are given concurrently with succinyleholine, similar neuromuscular blocking agents or cholinergic agonists such as bethanechol.

Carcinagenesis, Mutagentesis, Impairment of Fertirlty: In carcinogenicity studies conducted at dose levels up to

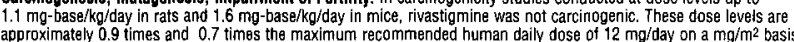
approximately 0.9 times and 0.7 times the maximum recommended human daily dose of $12 \mathrm{mg} / \mathrm{day}$ on a mg/m² basis. Rivastigmine was clastogenic in two in vitro assays in the presence, but not the absence, of metabolic activation. It caused
structural chromosomal aberrations in V79 Chinese hamster lung cells and both structural and numerical (polyploidy) chrostructural chromosomal aberrations in V79 Chinese hamster lung cells and both structural and numerical (polyploidy) chromosomal aberrations in human peripheral blood lymphocytes. Rivastigmine was not genotoxic in three in vitro assays: the
Ames test, the unscheduled DNA synthesis (UDS) test in rat hepatocytes (a test for induction of ONA repair synthesis), arid Ames lest, the unscheduled DNA synthesis (UDS) test in rat hepatocytes (a test for induction of ONA repair synthesis), an
the HGPRT test in V79 Chinese hamster cells. Rivastigmine was not clastogenie in the in vivo mouse micronucleus test. Rivastigmine had no effect on fertility or reproductive performance in the rat at dose levels up to $1.1 \mathrm{mg}$-base/kg/day. This

Pregnancy: Pregnancy Category B: Reproduction studies conducted in pregnant rats at doses up to $2.3 \mathrm{mg}$-base/kg/day (approximately 2 times the maximum recommended human dose on a $\mathrm{mg}^{2} / \mathrm{m}^{2}$ basis) and in pregnant rabbits at doses up to of teratogenicity Studies in rats showed slightly decreased fetalpup weights, usually at doses causing some maternal toxicity decreased weights were seen at doses which were several fold lower than the maximum recominended human dose on a $\mathrm{mg} / \mathrm{m}^{2}$ basis. There are no adequate or weill-controlled studies in pregnant women. Because animal reproduction studies are not always predictive of human response, Exelon should be used during pregnancy only if the potential benefit justifies the potential risk to the tot tus.

Nursing Mothers: it is not known whether rivastigmine is excreted in human breast milk. Exelon has no indication for use in

Pediatric Uss: There are no adequate and well-controlled trials documenting the safety and efficacy of Exelon in any illnes occurring in children.

ADVERSE REAGTIOHS: Adverso Events Laading to Discontlnuation: The rate of discontinuation due to adverse everits in controlled chinical trials of Exelon $\$$ (rivastigmine tartrate) Was $15 \%$ tor patients receiving $6-12 \mathrm{mg} /$ day compared to $5 \%$ for
patients on placebo during forced weekly dose titration. While on a maintenance dose, the rates were $6 \%$ for patients on

The most common adverse events leading to discontinuation, defined as those occurring in at least $2 \%$ of patients and at

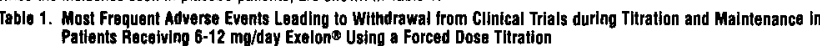
Study Phass

\begin{tabular}{|c|c|c|c|c|c|c|}
\hline \multirow[t]{2}{*}{ Study Phaso } & \multicolumn{2}{|c|}{ Tilration } & \multicolumn{2}{|c|}{ Maintenance } & \multicolumn{2}{|c|}{ Overall } \\
\hline & $\begin{array}{l}\text { Placebo } \\
\text { (n=868) }\end{array}$ & $\begin{array}{c}\text { Exalon } \\
26-12 \mathrm{mg} / \mathrm{day} \\
(\mathrm{n}=1189)\end{array}$ & $\begin{array}{l}\text { Placebo } \\
(n=788)\end{array}$ & $\begin{array}{c}\text { Exelon } \\
26-12 \mathrm{mg} / \mathrm{day} \\
(\mathrm{n}=987)\end{array}$ & $\begin{array}{l}\text { Placebo } \\
(\mathrm{n}=868)\end{array}$ & $\begin{array}{c}\text { Exolon } \\
=6-12 \mathrm{mg} / \mathrm{day} \\
(\mathrm{n}=1189)\end{array}$ \\
\hline $\begin{array}{l}\text { Event / \% } \\
\text { Discontinuling } \\
\text { Nausea } \\
\text { Vomiting } \\
\text { Anorexiá } \\
\text { Dizziness }\end{array}$ & $\begin{array}{r}<1 \\
<1 \\
0 \\
<1\end{array}$ & $\begin{array}{l}8 \\
4 \\
2 \\
2\end{array}$ & $\begin{array}{l}<1 \\
<1 \\
<1 \\
<1\end{array}$ & $\begin{array}{l}1 \\
1 \\
1 \\
1\end{array}$ & $\begin{array}{l}1 \\
<1 \\
<1 \\
<1\end{array}$ & $\begin{array}{l}8 \\
5 \\
3 \\
2\end{array}$ \\
\hline
\end{tabular}

Most Frequent Adverse Cilnical Events Soen In Association with the Use of Exelon: The most common adverse events, defined as those occurring at a frequency of at least $5 \%$ and twice the placebo rate, are largely predicted by Exelon's choliner-

Gastrointestinal Adverse Reactlons: Exelon use is associated with significant nausea, vomiting, and weight loss (see

Adverse Events Reported In Controlled Trials: Table 2 lists treatment emergent signs and symptoms that were reported in at least $2 \%$ of patients in placebo-controlled trials and for which the rate of occurrence was greater for patients treated with used to predict the freguency of adverse events in the course of us ual medical practice when patient characteristics and other used to predict the frequency of adverse events in the course of usual medical practice when patient characteristics and other
tactors may differ from those prevailing during clinical studies. Similarly, the cited frequencies cannot be directly compared with figures obtained from other clinical investigations involving different treatments, uses, or investigators. An inspection of and nequencies, how tever, does provide he presch in wh one basis by which the

in general, adverse reactions were less frequent later in the course of treatment.

No systematic effect of race or age could be determined on the incidence of adverse events in the controlled studies. Nausea Even

Table 2. Adverse Events Reported in Controlled Clinical Trials in at Least $2 \%$ of Pattents Receiving Exelono

\begin{tabular}{|c|c|c|}
\hline Body System/Adverse Event & $\begin{array}{l}\text { Placebo } \\
\text { (n=868) }\end{array}$ & $\begin{array}{c}\text { Exeion } \\
(6-12 \mathrm{mg} / \mathrm{day}) \\
(\mathrm{n}=1189)\end{array}$ \\
\hline $\begin{array}{l}\text { Percent of Patients with any Adverse Event } \\
\text { Autonomic Hervous System }\end{array}$ & 79 & 92 \\
\hline $\begin{array}{l}\text { Autonomic Hervous System } \\
\text { Sweating increased } \\
\text { Syncope }\end{array}$ & $\begin{array}{l}1 \\
2\end{array}$ & $\begin{array}{l}4 \\
3\end{array}$ \\
\hline $\begin{array}{l}\text { Body as a Whole } \\
\text { Accidental Trauma } \\
\text { Fatigue } \\
\text { Asthenia } \\
\text { Malaise } \\
\text { Influenza-like Symptoms } \\
\text { Weight Decrease }\end{array}$ & $\begin{array}{r}9 \\
5 \\
2 \\
2 \\
2 \\
<1\end{array}$ & $\begin{array}{r}10 \\
9 \\
9 \\
6 \\
5 \\
3 \\
3\end{array}$ \\
\hline $\begin{array}{l}\text { Cardiovascular Disarders, General } \\
\text { Hypertension }\end{array}$ & 2 & 3 \\
\hline $\begin{array}{l}\text { Central and Perlpheral Nervous System } \\
\text { Dizziness } \\
\text { Headache } \\
\text { Somnolence } \\
\text { Tremor }\end{array}$ & $\begin{array}{r}11 \\
12 \\
3 \\
4\end{array}$ & $\begin{array}{r}21 \\
17 \\
5 \\
4\end{array}$ \\
\hline $\begin{array}{l}\text { Gastrointestinal System } \\
\text { Nausea } \\
\text { Vomiting } \\
\text { Diarrnea } \\
\text { Anorexia } \\
\text { Abdominal Pain } \\
\text { Dyspepsia } \\
\text { Constipation } \\
\text { Flatulence } \\
\text { Eructation }\end{array}$ & $\begin{array}{r}12 \\
6 \\
11 \\
3 \\
6 \\
4 \\
4 \\
2 \\
1\end{array}$ & $\begin{array}{r}47 \\
31 \\
19 \\
17 \\
13 \\
9 \\
5 \\
4 \\
2\end{array}$ \\
\hline $\begin{array}{l}\text { Psychiatric Disorders } \\
\text { Insormnia } \\
\text { Confusion } \\
\text { Depression } \\
\text { Anxiety } \\
\text { Hallucination } \\
\text { Aggressive Reaction }\end{array}$ & $\begin{array}{l}7 \\
7 \\
4 \\
3 \\
3 \\
2\end{array}$ & $\begin{array}{l}9 \\
8 \\
6 \\
5 \\
4 \\
3\end{array}$ \\
\hline $\begin{array}{l}\text { Resistance Mechanlsm Disorders } \\
\text { Urinary Tract Infection }\end{array}$ & 6 & 7 \\
\hline $\begin{array}{l}\text { Respiratory System } \\
\text { Rhinitis }\end{array}$ & 3 & 4 \\
\hline
\end{tabular}

Other adverse events observed at a rate of $2 \%$ or more on Exelon $6-12 \mathrm{mg} /$ day but at a greater or equal rate on placebo were chest pain, peripheral edema, vertigo, back pain, arthralgia, pain, bone fracture, agitation, nervousness, delusion, para-
noid reaction, upper respiratory tract infections, infection (general), coughing, pharyngltis, bronchitis, rash (general), urinary noid reaction,
incontinence.

Other Adverse Events Observed During Clinical Trials: Exelon has been administered to over 5297 individuals during clinica trials worldwide. 01 these, 4326 patients have been treated for at least 3 months, 3407 patients have been treated for at least over 3 years. With regard to exposure to the highest dose. 2809 patients were exposed to doses of $10-12 \mathrm{mg}, 2615$ patients treated for 3 months, 2328 patients treated for 6 months, 1378 patients treated for 1 year, 917 patients treated for 2 years, and 129 treated for over 3 years.

Treatment emergent signs and symptoms that occurred during 8 controlled clinical trials and 9 open-label trials in North America, Western Europe, Australia, South Africa, and Japan were recorded as adverse events by the clinical investigators using terminology of their own choosing. To provide an overall estimate of the proportion of individuals having similar types of events, the events were grouped into a smaller number of standardized categories using a modified WHO dictionary, and event trequencies were calculated across all studies. These categories are used in the listing below. The frequencies represent
the proportion of 5297 patients from these trials who experienced that event while receiving Exelon. All adverse events occurthe proportion of 5297 patients from these rrials who experienced that event while receiving Exelon. All adverse events occur-
ring in at least 6 pationts (approximately 0.1\%) are included, except for those already listed elsewhere in labeling, WHO terms ring in at least 6 patients (approximately $0.1 \%$ ) are included, except for those already listed elsewhere in labeling, WHo terms
too general to be informative, relatively minor events, or events untikely to be drug caused. Events are classified by body system and listed using the following definitions: trequent adverse events - those occurring in at least $1 / 100$ patients; infrequent adverse events - those occurring in $1 / 100$ to $1 / 1000$ patients. These adverse events are not necessarily related to Exelon treat-

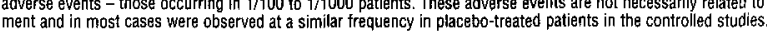
Autonomic Hervous System: Infrequent: Cold clammy skin, dry mouth, flushing, increased saliva.

Gody as a Whole: Frequent: Accidental trauma, fever, edema, allergy, hot flushes, rigors. Infrequent: Edema periorbital or Cal, hypothermia, edema, feeling cold, halitosis.

Cardiovascular System: Frequent: Hypotension, postural hypotension, cardiac failure.

Central and Peripheral Nervous System: Frequent: Abnormal gaif, ataxia, paraesthesia, convulsions. Infrequent: Paresis, apraxia, aphasia, dysphonia,

Endocrine System: Infrsquent: Goitre, hypothyroidism.

Gastrolntestinal System: Frequent: Fecal incontinence, gastritis. Infrequent: Dysphagia, esophagttis, gastric ulcer, gastritis, gastroesophageal reflux, Gl hemorrhage, hernia, intestinal obstruction, melena, rectal hemarrhage, gastroenteritis, ukcerative stomatitis, duodenal ulcer, hematemesis, gingivitis, tenesmus, pancreatitis, colitis, glossitis.

Hearing and Vesilibular Disorders: Frequent: Tinnitus.

Heart Rate and Rhythm Disorders: Frequent: Atrial fibrillation, bradycardia, palpitation. Infrequent: AV block, bundle branch block, sick sinus syndrome, cardiac arrest, supraventricular tachycardia, exfrasystoles, tachycardia.

Liver and Blllary System Disorders: Infrequent: Abnormal hepatic function, cholecystitis.

Metabolic and Nutrltlonal Dlsorders: Frequent: Dehydration, hypokalemia. Infrequent: Diabetes mellitus, gout, hypercho-

Musculosklal Disorders: Frequent. Arthrits, leg cramps, myaloia infrequent Cramps hernia muscle weakness.

Myo-, Endo-, Perlcardial and Valve Dlsorders: Frequent: Angina pectoris, myocardial infarction.

Platelet, Bleeding, and Clotting Dlsorders: Frequent: Epistaxis. Infrequent: Hematoma, thrombocytopenia, purpura. Psychiatric Oisorders: Frequent: Paranoid reaction, confusion. Infrequent: Abnormal dreaming, amnesia, apathy, delirium dementia, depersonalization, emotional lability, impaired conceris

Red Blood Cell Disorders: Frequent: Anemia. Infrequent: Hypochromic anemia.

Reproductlve Disorders (Female \& Male): Infrequent: Breast pain, impotence, atrophic vaginitis.

Resistance Mechanism Disorders: Infrequent: Cellulitis, cystitis, herpes simplex, otitis media.

Pespiratory System: Infrequent: Bronchospasm, laryngitis, apnea.

Skln and Appendages: Frequent: Rashes of various kinds (maculopapular, eczema, bullous, exioliative, psoriatorm, erythemaSkin and Appendages: Frequent Rashes of various kinds (maculopapular
tous). infrequent: Alopecia, skin ulceration, uticaria, dermatitis contact.

Special Senses: Intrequent: Perversion of taste, loss of taste

Urinary System Disorders: Frequent: Hematuria. Infrequent: Albuminuria, oliguria, acute renal failure, dysuria, micturition urgency, nocturia, polyuria, renal calculus, urinary retention.

Vascular (extracardiac) Disorders: Infrequent: Hemorrhoids, peripheral ischemia, pulmonary embolism, thrombosis,

Vision Disorders Frequent: Cataract Infrequent: Coniunctival hemorrhage, blepharitis, diplopia, eve pain, glaucoma. White Cell and Resistance Disorders: Infrequent: Lymphadenopathy, leukocytosis

Post-Introduction Reports: Voluntary reports of adverse events temporaliy associated with Exelon that have been received

since market introduction that are not listed above, and that may or may not be causally related to the drug include the

Skin and Appendages: Stevens-Johnson syndrome.

REV: JANUARY 2001

Printed in U.S.A.

$12000-74$
89007403

Manufactured by

Novartis Pharma AG

Novartis Pharmaceuticicals Corporation

East Hanover, New Jersey 07936

O2001 Novartis 